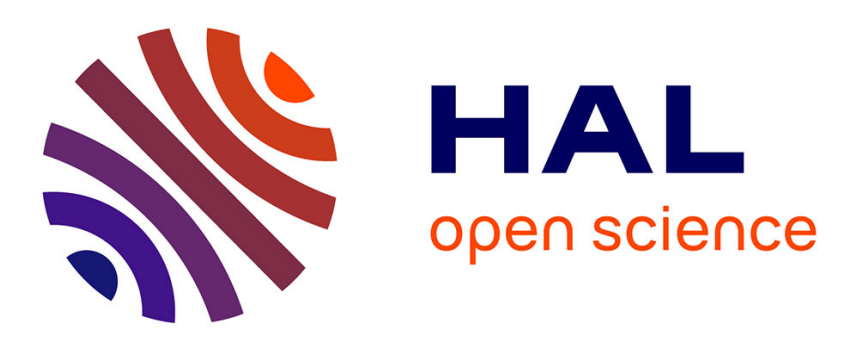

\title{
Sovereign Default and Liquidity: The Case for a World Safe Asset
}

François Le Grand, Xavier Ragot

\section{To cite this version:}

François Le Grand, Xavier Ragot. Sovereign Default and Liquidity: The Case for a World Safe Asset. Journal of International Economics, Elsevier, 2021, 131, pp.103462. 10.1016/j.jinteco.2021.103462 . hal-03501397

\section{HAL Id: hal-03501397 \\ https://hal-sciencespo.archives-ouvertes.fr/hal-03501397}

Submitted on 30 Dec 2021

HAL is a multi-disciplinary open access archive for the deposit and dissemination of scientific research documents, whether they are published or not. The documents may come from teaching and research institutions in France or abroad, or from public or private research centers.
L'archive ouverte pluridisciplinaire HAL, est destinée au dépôt et à la diffusion de documents scientifiques de niveau recherche, publiés ou non, émanant des établissements d'enseignement et de recherche français ou étrangers, des laboratoires publics ou privés. 


\title{
Sovereign Default and Liquidity: The Case for a World Safe Asset*
}

\author{
François Le Grand $\quad$ Xavier Ragot ${ }^{\dagger}$
}

October 20, 2020

\begin{abstract}
This paper presents a positive and normative study of a world financial market when sovereign countries can default on their debt. We construct a tractable model that enables us to study sovereign default in general equilibrium. The amount of safe assets is thus endogenous and determined by international risk-sharing. We characterize the equilibrium structure and we show that the market equilibrium can generate multiple equilibria. In addition, the market equilibrium is not constrained-efficient because countries do not fully internalize the value of their debt being used as liquidity. We prove that a world fund issuing a safe asset increases aggregate welfare. The fund's relationship with the IMF's Special Drawing Rights is discussed.
\end{abstract}

JEL: E21, E32, F34, 019.

Keywords: Sovereign default, safe asset, international liquidity.

\section{Introduction}

The global economy exhibits two related features. The first is the pervasiveness of sovereign default. The largest default in history (by present value) was the 2012 Greek debt restructuring,

${ }^{*}$ We thank Klaus Adam, Manuel Amador, Cristina Arellano, Édouard Challe, Emmanuel Farhi, Jonathan Heathcote, Hugo Hopenhayn, Vincenzo Quadrini, Pierre-Olivier Weill, and seminar participants at ETH Zurich, the European Economic Association meeting, the Federal Reserve Bank of Minneapolis, ENSAE-Crest, the NHH$\mathrm{UiO}$ workshop, the University of Southern California, the University of California, Los Angeles, the Barcelona GSE Summer Forum, and the SED 2018, where an earlier version of this work was presented.

${ }^{\dagger}$ François Le Grand: emlyon business school, and ETH Zurich legrand@em-lyon.com; Xavier Ragot: SciencesPo-CNRS and OFCE, xavier.ragot@gmail.com. Corresponding Author: Xavier Ragot, SciencesPo, 28 rue des Saints-Pères, 75007 Paris, France. 
which covered more than $€ 200$ bn of privately held debt (Tomz and Wright, 2013). Current debates regarding a larger restructuring of Greek debt or the default of another developed country indicate that sovereign default may reach another order of magnitude in the near future. Even if the default risk fails to materialize, the fact that it is discussed is a clear indication that the perceived safeness of certain countries' public debt has deteriorated. The second feature affecting the global economy is the apparent shortage of safe assets, which explains the downward trend in the return on US public debt. ${ }^{1}$ These two facts are obviously related, as sovereign default almost mechanically reduces the quantity of safe assets. In addition, the quantity of safe assets affects real interest rate levels and the default probability through its effect on both the incentives to accumulate assets and the opportunity cost of default.

The goal of this paper is to investigate the interactions between the quantity of safe assets and sovereign default in general equilibrium. We are interested in both positive and normative questions. What are the determinants of the quantity of safe assets when sovereigns can choose to strategically default? Does the market economy generate too many defaults as a general equilibrium outcome? Should a world institution issue a safe asset? If so, how much should it issue? This last question was, for instance, discussed in policy circles at the IMF before the decision to issue Special Drawing Rights.

To help answer these questions, this paper presents a general equilibrium model of default where sovereigns can borrow or lend on international markets, and possibly default on their debt, in order to smooth idiosyncratic income shocks. Elaborating on the Eaton and Gersovitz (1981) literature, the basic friction we consider is the lack of a complete insurance market for country-specific risk. Countries can only issue non-contingent claims, on which they can default. Equilibrium default can occur when the debt burden is high in bad times and when the opportunity cost of default is low. Following the work of Aguiar and Gopinath (2006) and Arellano (2008), among others, this framework has become a benchmark for studying sovereign default (see Aguiar and Amador, 2015). In this literature, the authors assume that the riskless real interest rate is exogenous, which enables them to investigate the amount of debt and the

\footnotetext{
${ }^{1}$ Caballero and Farhi (2017), Barro, Fernández-Villaverde, Levintal, and Mollerus (2016), and Hall (2016), among others, discuss the effects of a shortage of safe assets. See also Gorton, Lewellen, and Metrick (2012) for a measure of the safe asset share in the US economy.
} 
default decision in rich environments (see the literature review below). Our contribution is to endogenize the world interest rate by developing a tractable general equilibrium model and to derive welfare analysis. Tractability is obtained using a quasi-linear utility function, as in Scheinkman and Weiss (1986), Lagos and Wright (2005), or Challe, LeGrand, and Ragot (2013), among others, which considerably simplifies the state-space.

We model the world economy as a continuum of countries borrowing and lending to one other to smooth idiosyncratic shocks. Countries can default on their debt, depending on the endogenous intertemporal cost of default. When countries default, they are temporarily excluded from the financial markets. The world interest rate is determined by the international financial market clearing system. Equilibrium in this economy is characterized by the default policy, world wealth distribution, and world interest rates. An alternative way of considering this economy is to think about a Bewley economy where agents face no exogenous credit constraint but may default if they find it optimal to do so. Surprisingly, the constrained-efficiency of market economies and of optimal policies in these environments has yet to be studied. To do so, we use the strategy of Davila, Hong, Krusell, and Rios-Rull (2012), developed in incomplete-market economies without default, in order to derive the constrained-efficient allocation. We then analyze the properties of the market economy, in particular welfare and the quantity of safe assets determining international risk-sharing. Tractability allows deriving general properties about the equilibrium structure with persistent shocks, and the nature of the participation constraints which must bind before default. We derive three main results.

First, we show that the aggregate saving is not always a monotonic function of the world interest rate. For a fixed default decision, countries' savings increase with the interest rate (the intensive margin). But when the interest rate increases, countries can also choose to postpone a default decision when they experience a bad idiosyncratic shock, implying that a larger number of countries borrow in equilibrium (the extensive margin). The net effect of both margins can generate a decrease in aggregate savings when the interest rate increases. These non-monotonic aggregate savings can in turn generate multiple equilibria.

Second, we show that the market equilibrium is constrained-inefficient. The reason being 
that when markets are incomplete, prices do not convey the right incentives to save. In other words, there is a pecuniary externality, implying a lack of risk-sharing and a shortage of safe assets in the market economy. Sovereigns do not properly internalize the social benefits of their debt as a safe asset for other countries in their net saving and default decisions, as markets are incomplete.

Third, we prove that introducing an International Financial Institution (IFI) increases aggregate welfare. The IFI issues interest-bearing assets that are financed by the voluntary contributions of member states. The IFI can implement full risk-sharing among member states, and default still occurs in general equilibrium. We calibrate the model using data on sovereign default and "disaster events" to reproduce both the default probability and income fluctuations.

As a final step, we verify that these results are robust to the introduction of a large country with positive mass - internalizing the effect of its saving decisions on the world financial market. Following Farhi and Maggiori (2018), we call this country the Hegemon. We prove that the main results hold. The introduction of an IFI still improves aggregate welfare by issuing outside liquidity.

The IFI and its asset supply are obviously reminiscent of the IMF Special Drawing Rights (SDRs). These SDRs were issued in the early 1970s after a global discussion about the scarcity of safe stores of value (see Williamson, 2009 for a short history). SDRs are interest-bearing assets, whose interest rate is determined weekly as the average interest rate on the money markets for a basket of currencies. ${ }^{2}$ There is nevertheless a main difference between the assets issued by the IFI in our model and SDRs.The interest rate on the assets issued by the IFI in our model should be linked to the interest paid by governments issuing safe assets rather than the interest on money markets, as is the case for SDRs. Our safe asset is not a currency but a remunerated store of value. In addition, the outstanding amount was smaller than $0.3 \%$ of world GDP in 2016, whereas we find a much higher amount in our simple numerical exercise.

\footnotetext{
${ }^{2}$ See the IMF website for a precise definition and SDR interest rate values: http://www.imf.org/external/ $\mathrm{np} / \mathrm{fin} / \mathrm{data}_{\mathrm{sdr}}$ ir.aspx.
} 
Literature review. This model provides positive and normative implications for sovereign default in general equilibrium. It follows the tradition of Eaton and Gersovitz (1981) based on incomplete insurance markets, which have been shown to be quantitatively relevant (Aguiar and Gopinath, 2006, Arellano, 2008, among others, as well as the recent survey of Aguiar and Amador, 2015). The same tools (incomplete insurance markets and strategic default) have been used to study household default in general equilibrium. Chatterjee, Corbae, Nakajima, and Ríos-Rull (2007) and Livshits, MacGee, and Tertilt (2007) use this model to compare the welfare effect of different legal frameworks on household default. Instead, we provide a tractable model to characterize the constrained-efficient equilibria using the methodology of Davila, Hong, Krusell, and Rios-Rull (2012) and provide a mechanism to decentralize it.

The quasi-linear framework allows us to characterize the equilibrium structure with persistent idiosyncratic shocks and a general saving set. In this case, it is known that policy and price functions may not be differentiable (Clausen and Strub, 2020), which makes the analysis more complex. To avoid these technicalities, Arellano (2008) considers i.i.d shocks and Chatterjee, Corbae, Nakajima, and Ríos-Rull (2007) consider a finite saving set. The unrestricted saving set together with persistent shocks allows us to show that our set-up features exactly two types of equilibrium, one with default as in Eaton and Gersovitz (1981) and another one without default, but with an endogenous credit limit as in Zhang (1997). This characterization may be of independent interest.

Our analysis stresses the role of the quantity of assets required to self-insure against idiosyncratic shocks. It is thus related to the recent literature on safe assets, in particular the literature focusing on the quantity of the risk-adjusted store of value provided by the market economy. Authors (Gorton, Lewellen, and Metrick, 2012, Barro, Fernández-Villaverde, Levintal, and Mollerus, 2016, Hall, 2016, and Caballero and Farhi, 2017, among others) have studied the implications of a possible lack of safe assets. Another large body of literature investigates the determinants of the quantity of world safe assets and of the interest rate (Mendoza, Quadrini, and Rios-Rull, 2009, Azzimonti, de Francesco, and Quadrini, 2014) and the decisions of sovereigns to strategically choose their level of public debt with roll-over risk (He, Krishnamurty, and Mil- 
bradt, 2019). Farhi and Maggiori (2018) propose a model of the international monetary system and study various market structures and frictions. We instead identify the distortions on the world financial markets in the absence of these strategic behaviors.

The source of multiple equilibria is new to the best of our knowledge, although other mechanisms generating equilibrium multiplicity have been discussed in the literature. First, a large body of literature has emphasized roll-over risk, following Calvo (1988) or Cole and Kehoe (2000). Recent references include Lorenzoni and Werning (2019) and He, Krishnamurty, and Milbradt (2019). In our model, this type of risk does not exist. Recently, Arellano, Bai, and Lizarazo (2017) have proved the presence of multiple equilibria generated by negative wealth shocks on risk-adverse lenders. Our mechanism for equilibrium multiplicity is different. It is based on the endogeneity of the quantity of safe assets, which affects both the cost of self-insurance and the incentives to default. Indeed, when the interest rate is exogenous, the value functions can be expected to be unique in our Eaton-Gersovitz environment as shown by Auclert and Rognlie $(2016) .^{3}$

Section 2 presents the environment. Section 3 solves the model for the partial equilibrium. Section 4 examines equilibrium multiplicity. Section 5 discusses constrained-efficiency and the provision of outside liquidity, through an IFI. Section 6 considers possible extensions and Section 7 concludes.

\section{Environment}

\subsection{Set-up}

Time is discrete $t=1, \ldots, \infty$. We first model the world economy as a continuum of small open economies. Countries are distributed in each period $t$ according to a uniform distribution $G$ over a segment $I$ of length 1 , without mass points. ${ }^{4}$ All countries are thus small and have no market power in the world financial market. We discuss in Section 6 the case where a large country has

\footnotetext{
${ }^{3}$ Finally, there is a different literature stream on default in general equilibrium with complete insurance markets, where default generates utility costs. See, for instance, Dubey, Geanakoplos, and Shubik (2005), among others.

${ }^{4}$ This representation of the world economies follows Clarida (1990) or Bai and Zhang (2010). There is a body of literature examining the applicability of the law of large numbers in continuum economies - see Feldman and Gilles (1985) and Green (1994), among others. Here, we simply assume that the law of large numbers applies.
} 
a financial market power, to verify the generality of our results.

Each small open economy has a risky production technology, and a benevolent government maximizes utility on behalf of a unit mass of identical consumers. Countries face idiosyncratic production shocks, and there is no aggregate shock at the world level.

Each country has identical, additive, and time-separable preferences over streams of consumption $\left(c_{t}\right)_{t \geq 0}$ and labor supply $\left(l_{t}\right)_{t \geq 0}$. The period utility function over consumption $c$ and labor supply $l$ is $u(c)-l$, where the consumption utility function $u$ is increasing, twice continuously differentiable, and concave. In the applications below, $u$ will be CRRA: $u(c)=\left(c^{1-\sigma}-1\right) /(1-\sigma)$ for $\sigma>1$ and $\mathrm{u}(c)=\ln (c)$ otherwise. The micro-foundation for this linear disutility of labor is the existence of both indivisible labor and a complete market within the country, as shown by Hansen (1985) and Rogerson (1988). ${ }^{5}$ In each country, the government maximizes the intertemporal welfare $\sum_{t=0}^{\infty} \beta^{t}\left(u\left(c_{t}\right)-l_{t}\right)$, where $\beta \in(0,1)$ is the constant discount factor.

Countries face a productivity risk that can be neither avoided nor insured. The productivity status of a given country can be in one of two states, which are described as productive (state $p$ ) and unproductive (state $u$ ). When a country is productive, it has access to a linear production technology, which transforms $l$ units of labor into $l$ units of final goods. The country's labor supply can, in addition, be freely adjusted in every period. When a country is unproductive, it is restricted to supplying an amount $\bar{l}$ of labor, such that $u^{\prime}(\bar{l})>1$. This restriction implies that the marginal utility of consumption for a country in a productive state is smaller than that of a country in an unproductive state - this result is stated and proven in Lemma 1 of Appendix B.

The productivity status follows a first-order Markov chain with the transition matrix $\Pi=$ $\left[\begin{array}{cc}\alpha & 1-\alpha \\ 1-\rho & \rho\end{array}\right] \in(0,1)^{4}$, where the probability $1-\alpha$ is the probability of switching from state $p$ in the current period to state $u$ in the next one, for example. The stationary distribution of this process implies that the share of productive countries is $n^{p}=(1-\rho) /(2-\alpha-\rho)$, and the share of unproductive countries is $1-n^{p}$.

\footnotetext{
${ }^{5}$ The utility function is used by Lagos and Wright (2005) in a matching environment and by Scheinkman and Weiss (1986) and Challe, LeGrand, and Ragot (2013), among others, in an incomplete-market environment without default. It simplifies the analysis, as shown below. We use a CRRA utility function with an IES smaller than 1 (which is the empirically relevant case - see for instance Havránek, 2015, for a review) as a benchmark to simplify the algebra. Our results do not depend on this assumption, and a more general utility function could be considered, as we explain in Appendix B.2. This justifies why we keep the notation $u$ throughout the paper.
} 


\subsection{Financial markets and default}

As is standard in the literature on sovereign default, following Eaton and Gersovitz (1981) and Bulow and Rogoff (1989), international financial markets are assumed to be plagued by two frictions. First, markets are incomplete for the country-specific production shock. Second, countries can default on their debt, but at the cost of being temporarily excluded from the financial markets. We assume that the current productivity status and the asset volume for each country are observable when debt is traded on international markets. If a country defaults on its debt, it is excluded from international markets and has to live in a state of autarky before potentially coming back to international financial markets. Excluded countries are still affected by the productivity shock. When unproductive, excluded countries cannot reenter the financial markets. When productive, they have the probability $\theta \in(0,1)$ of reentering the financial markets in every period. Countries are endowed with zero financial wealth when they reenter the financial markets.

Debt is traded through a unit mass of competing risk-neutral financial intermediaries. Saving countries lend to intermediaries, and borrowing countries borrow from them. Financial intermediaries diversify their risk across countries and act as devices for pooling idiosyncratic risk. Since there is no aggregate risk, financial intermediaries can charge a credit risk premium to borrowers according to their default probability, and savers can save in a safe asset.

We denote by $q\left(B^{\prime}, s\right)$ the price of a claim on one unit of a next period good for a country that chooses an amount of asset $B^{\prime}$ and that has the production status $s=\{p, u\}$. If $B^{\prime}>0$, the country is saving in a safe asset of price $q\left(B^{\prime}, s\right)=q$. The real interest rate on the safe asset is simply $1+r \equiv \frac{1}{q}$. If $B^{\prime}<0$, the country is borrowing. Since intermediaries are perfectly diversified, the price $q\left(B^{\prime}, s\right)$ can be expressed as:

$$
q\left(B^{\prime}, s\right)=q\left(1-\delta\left(B^{\prime}, s\right)\right)
$$

where $\delta\left(B^{\prime}, s\right)$ is the next-period default probability of a country choosing a debt $B^{\prime}$ while its current status is $s \in\{p, u\}$. Importantly, both the price of a safe asset $q$ and the default probability $\delta\left(B^{\prime}, s\right)$ will be general equilibrium endogenous outcomes. 
A country in state $s \in\{p, u\}$, endowed with the beginning-of-period wealth $B$, trading an amount of debt $B^{\prime}$, and supplying a labor quantity $l$, will have consumption equal to:

$$
c=l+B-q\left(B^{\prime}, s\right) B^{\prime}
$$

If the country is in a productive state, it can then freely adjust its labor effort $l$. If unproductive, the country will supply the fixed amount $l=\bar{l}$.

Since the default probability $\delta\left(B^{\prime}, s\right)$ is not necessarily continuous for the debt level $B^{\prime}$, the budget set may not be convex. However, although the problem is not convex, it can be written in recursive form (see Stokey, Lucas, and Prescott, 1989, Theorem 9.4 and Auclert and Rognlie, 2016 for the properties of the equilibrium structure), which allows us to simplify the exposition and to derive the necessary first-order conditions.

\subsection{Market clearing and equilibrium}

We define $V_{s}^{o}(B)$ as the value function of a country that participates in the financial markets, that starts the current period with the asset holding $B$, and that has the productivity status $s \in\{p, u\} .{ }^{6}$ The superscript $o$ denotes a participating country that has the option to default on $B$. The country then decides whether to default or repay its debts by choosing the option associated with the highest welfare. We denote by $V_{s}^{c}(B)$ the value function of a country deciding to repay the debt $B$, while its status is $s$. The superscript $c$ indicates that the country decides to continue to honor its debts. Similarly, the value function $V_{s}^{a}$ is the value function of a country that is in autarky, after defaulting for instance. These value functions are defined in equations (4) and (5) below. The value function $V_{s}^{o}(B)$ is thus equal to the maximum between the value functions associated with debt repayment or default. Formally:

$$
\forall B, \forall s \in\{p, u\}, \quad V_{s}^{o}(B)=\max \left\{V_{s}^{c}(B), V_{s}^{a}\right\}
$$

Let us now turn to the expression of value functions $V^{a}$ and $V^{c}$. Since the probability of defaulting countries reentering the financial markets when productive with zero wealth is $\theta$, the

\footnotetext{
${ }^{6}$ For the sake of simplicity, we follow the notation of Arellano (2008).
} 
value function associated with autarky can be expressed as:

$$
\begin{aligned}
& V_{p}^{a}=\max _{l}(u(l)-l)+\beta \alpha\left(\theta V_{p}^{o}+(1-\theta) V_{p}^{a}\right)+\beta(1-\alpha) V_{u}^{a}, \\
& V_{u}^{a}=u(\bar{l})-\bar{l}+\beta(1-\rho)\left(\theta V_{p}^{o}+(1-\theta) V_{p}^{a}\right)+\beta \rho V_{u}^{a} .
\end{aligned}
$$

In these two equations, the country is excluded from the financial markets and trades no assets, and the associated value functions are thus constant. The whole production $l$ or $\bar{l}$ of a period is consumed within the same period.

When a country participates in the financial markets and chooses not to default in the current period, the value function $V^{c}$ can be expressed as follows, for any debt endowment $B$ :

$$
\begin{aligned}
& V_{p}^{c}(B)=\max _{l, B^{\prime}} u\left(l+B-q\left(B^{\prime}, s\right) B^{\prime}\right)-l+\beta\left(\alpha V_{p}^{o}\left(B^{\prime}\right)+(1-\alpha) V_{u}^{o}\left(B^{\prime}\right)\right), \\
& V_{u}^{c}(B)=\max _{B^{\prime}} u\left(\bar{l}+B-q\left(B^{\prime}, s\right) B^{\prime}\right)-\bar{l}+\beta\left((1-\rho) V_{p}^{o}\left(B^{\prime}\right)+\rho V_{u}^{o}\left(B^{\prime}\right)\right),
\end{aligned}
$$

where we use the budget constraint (2) to substitute for the consumption expression. As the value functions $V_{s}^{c}$ for $s=p, u$ are increasing in the wealth amount $B$, we can define the quantities $\bar{B}^{s} \in \mathbb{R} \cup\{-\infty\}, s=p, u$ as:

$$
\bar{B}^{s}=\min \left\{B \in \mathbb{R} \mid V_{s}^{c}(B) \geq V_{s}^{a}\right\}, s=p, u .
$$

In other words, the quantity $\bar{B}^{s}$ is the state-contingent threshold such that a country, in state $s$, endowed with a wealth level above the threshold will decide not to default.

Finally, we provide the expression for financial market clearing. For the sake of generality, we assume that the asset supply consists of a fixed amount of outside liquidity in quantity $B^{\text {out }}$. This outside liquidity could for instance be supplied by countries or institutions that are not exposed to the idiosyncratic risks under investigation (such as a subset of developed countries for instance). ${ }^{7}$ In the absence of such outside liquidity, we simply set $B^{\text {out }}=0$. If we recall that countries are distributed along the segment $I$ with the distribution $G$, financial market clearing

\footnotetext{
${ }^{7}$ Another solution to micro-found the outside liquidity $B^{\text {out }}$ would be to consider non-zero recovery amounts, as presented in model extensions of Section 6. However, such a solution would make the partial equilibrium analysis more complex. Outside liquidity is a simple mechanism that does not obfuscate partial equilibrium analysis, while still offering general equilibrium multiplicity - see Section 4.1.
} 
can be formalized as follows:

$$
\int_{i \in I} q\left(B^{i}, s^{i}\right) B^{i} G(d i)+q B^{\text {out }}=0
$$

where $B^{i}$ is the asset demand of country $i \in I$ in the current period. We focus on the steady state equilibrium where the price of the safe asset $q$ is constant.

We provide a more formal definition of the equilibrium.

Definition 1 (Competitive equilibrium) A competitive equilibrium is the collection of a price $q$, risk premia $(\delta(B, s))_{s=u, p, B \in \mathbb{R}}$, and policy functions $\left(B^{\prime}(B, s)\right)_{s=u, p, B \in \mathbb{R}},(l(B, p))_{B \in \mathbb{R}}$, such that: (i) for a given price $q$ and given risk premia $(\delta(B, s))_{s=u, p, B \in \mathbb{R}}$, policy functions solve the program (3)-(7); (ii) the risk premia are consistent with perfect competition and full diversification for financial intermediaries; and (iii) the price $q$ is such that the financial market clears, i.e., equation (9) holds.

\section{Partial equilibrium analysis}

Quasi-linearity in the labor supply considerably simplifies the analysis of the equilibrium. We focus in this section on the partial equilibrium analysis, i.e. with a given asset price $q$. We will turn to general equilibrium in Section 4.

\subsection{The structure of market equilibria}

To begin with, the first-order condition for the labor supply $l$ of productive countries in (6) implies that the consumption level of productive countries, denoted by $c_{0}$, is defined by $c_{0}=$ $u^{\prime-1}(1)$. Using the budget constraint (2), the value function (6) of productive participating (i.e., not in the default state) countries becomes:

$$
V^{c}(B, p)=V^{c}(0, p)+B
$$

which is thus linear in the beginning-of-period asset endowment. All productive non-defaulting countries therefore have the same marginal utility, which is independent of their beginning-ofperiod endowment. Deriving the first order-conditions for the saving choice of participating 
productive countries yields:

$$
q\left(B^{\prime}\right)=\beta\left(\alpha+(1-\alpha) u^{\prime}\left(c_{u}\left(B^{\prime}\right)\right)\right)
$$

where $B^{\prime}$ is the chosen level of savings, which affects the price due to the price schedule (1), and $c_{u}\left(B^{\prime}\right)$ is their next-period consumption if they become productive with a wealth level $B^{\prime}$. The previous expression shows that all productive countries have the same Euler equation, which is independent of the beginning-of-period wealth $B$ (as the marginal utility of consumption of productive countries is 1 and is independent of $B$ ). As a consequence, all productive countries choose to save the same amount, denoted as $B_{0}$, which is a standard outcome in quasi-linear environments.

Similarly, the derivation of the first-order condition for a participating unproductive country endowed with asset holdings $B$ leads to the following equation:

$$
q\left(B^{\prime}\right) u^{\prime}\left(c_{u}(B)\right)=\beta\left(1-\rho+\rho u^{\prime}\left(c_{u}\left(B^{\prime}\right)\right)\right)
$$

where as in (11), the quantity $B^{\prime}$ is the current saving choice. As in the productive case, all unproductive countries with the same asset endowment $B$ choose the same saving quantity $B^{\prime}$.

These two properties imply that the saving (or borrowing) decision of countries simply depends on their idiosyncratic production history, and more precisely, on the number of consecutive periods in the unproductive status. The equilibrium is thus characterized by a sequence of asset holdings $\left(B_{k}\right)_{k \geq 0}$, such that all productive countries participating in financial markets save $B_{0}$ while participating countries that are unproductive for $k \geq 1$ consecutive periods save the same amount $B_{k}$. Similarly, the consumption level of a country only depends on the number of consecutive periods in unproductive status, and we denote by $c_{k}, k \geq 0$ the consumption level of a country unproductive for the last $k$ periods. Two points are worth noting. First, our description is silent regarding the presence of default or not. Second, it is also silent regarding potential episodes where participation constraints (i.e., the choice of $\bar{B}^{u}$ or $\bar{B}^{p}$ ) were binding.

To avoid discussing irrelevant cases, we focus the remainder of the analysis on $1>q>\beta$, which is equivalent to $r>0$ and $\beta(1+r)<1$. It is known that the latter condition is necessary 
for an equilibrium to exist in incomplete market economies (Bewley, 1983, and Chamberlain and Wilson, 2000) - otherwise, countries would accumulate debt infinitely, which cannot be an equilibrium.

The following proposition provides a characterization of some elements of the equilibrium, independently of whether equilibrium features default or not.

Proposition 1 (Partial requilibrium characteristics) When the asset price is given, the equilibrium, independently of default or not, presents the following features:

1. The savings of unproductive countries $B_{k}$ are decreasing with the number $k$ of consecutive unproductive periods.

2. The state-contingent default threshold is higher in the unproductive state than in the productive one: $0>\bar{B}^{u}>\bar{B}^{p}$.

3. There is no optimal asset level in the open set $\left(\bar{B}^{p}, \bar{B}^{u}\right)$.

4. There is no equilibrium where the participation constraint never binds.

All proofs can be found in Appendix B. Proposition 1 summarizes key features of the equilibrium structure when the asset price is given. The first item states that the more countries remain unproductive, the less they save and the more they borrow. This intuitive result requires nevertheless a formal proof. The intuition is that, should wealth increase between two consecutive unproductive periods, then the country would end up accumulating an infinite amount of wealth.

The second item states that the state-contingent default threshold (in terms of wealth) is higher for unproductive countries than for productive ones. In other words, if a productive country is defaulting for a given level of debt, then an unproductive country will also default for this exact debt level. Again, this result is not direct to derive, and its proof relies on the tractability of our framework.

The third item states that a country will never optimally choose an asset demand in $\left(\bar{B}^{p}, \bar{B}^{u}\right)$. Alternatively, any optimal asset choice in the closed set $\left[\bar{B}^{p}, \bar{B}^{u}\right]$ is either $\bar{B}^{p}$ or $\bar{B}^{u}$. 
The fourth item states that there is no equilibrium for which the participation constraint, neither in the productive nor in the unproductive state, never binds. This means that the credit constraint must bind at least once in any equilibrium. Put it differently, the natural borrowing limit is always below participation constraints $\bar{B}^{p}$ and $\bar{B}^{u}$. This result rules out equilibria where countries would always have an interior solution to their individual program. ${ }^{8}$

Proposition 1 has important consequences for the equilibrium structure and restricts the possible admissible equilibria. Following Item 1, asset holdings must decrease with $k$ and then, because of Item 4 , must hit one of the two thresholds. First, when the constraint $\bar{B}^{u}$ is hit in a given period, the country must remain constrained in the next period. Indeed, it cannot opt for an asset choice $B$ such that $B>\bar{B}^{u}$ because of Item 1, nor such that $\bar{B}^{p}<B<\bar{B}^{u}$ because of Items 2 and 3. In other words, the country endowed with $\bar{B}^{u}$ can only choose $\bar{B}^{u}$ again or $\bar{B}^{p}$. Second, the constraint $\bar{B}^{p}<\bar{B}^{u}$ can be hit either while being endowed with any wealth $B \geq \bar{B}^{u}$ in the previous period ( $B=\bar{B}^{u}$ is not necessary). Hitting $\bar{B}^{p}$ implies default if the country remain unproductive for one additional period.

Overall, we can deduce from Proposition 1 that only two types of equilibria - in addition to autarky - are possible, depending on which thresholds are hit. The first equilibrium corresponds to asset choices hitting $\bar{B}^{u}$, but not $\bar{B}^{p}$. This equilibrium, investigated in Zhang (1997) among others, features no default and is analyzed in Section 3.3. ${ }^{9}$ The second equilibrium features asset choices reaching $\bar{B}^{p}$ (and possibly $\bar{B}^{u}$ in the previous period). In this equilibrium, analyzed in Section 3.2, some countries do default, as in Eaton and Gersovitz (1981).

Before we turn to the analysis of equilibria, we proceed with the expression of budget constraints. We denote by $D \leq \infty$ the number of consecutive unproductive periods after which a country defaults. The case $D=\infty$ corresponds to a no-default equilibrium and $D<\infty$ to a default equilibrium, and the expressions below are valid for all possible equilibria. A country unproductive for $k$ periods, endowed by $B_{k-1}$, chooses the consumption $c_{k}$ and the asset holding

\footnotetext{
${ }^{8}$ In particular, there is no equilibrium where unproductive countries would converge asymptotically (and never reaching a credit) toward a natural credit limit. The possibility of default prevents this equilibrium to exist. The proof of this result is simplified if $u^{\prime}(0)<\infty$ or $u(0)=-\infty$ (as in the CRRA utility function that we consider). In the case of a utility function fulfilling $u^{\prime}(0)=\infty$ and $u(0)>-\infty$, another sufficient condition is required (see equation (56) in Appendix B.2).

${ }^{9}$ This literature did not consider the existence of a default equilibrium, assuming that the no-default equilibrium is always preferred.
} 
$B_{k}$. If $k<D$, the country will not default in the next period and the asset price $q\left(B_{k}\right)$ is equal to $q$. The budget constraint (2) becomes then:

$$
B_{k-1}=c_{k}-\bar{l}+q B_{k}, k=1, \ldots, D-2 .
$$

If $k=D-1$ (meaning $D<\infty$ ), the country will default in period $D$ if it remains unproductive (therefore with probability $1-\rho)$. The asset price $q\left(B_{D-1}\right)$ is thus equal to $q(1-\rho)$ and the budget constraint (2) is:

$$
B_{D-2}=c_{D-1}-\bar{l}+q(1-\rho) B_{D-1}
$$

We finally consider the labor supply of productive countries. Since productive countries all choose the same asset holding and the same consumption level, their labor supply has to adjust to account for differences in beginning-of-period endowment. This endowment depends on the country's previous period status and in particular on the number of consecutive unproductive periods in the previous period. Consequently, we denote by $l_{k 0}$ the labor supply of a productive country that has been unproductive for the previous $k$ periods and has just returned to productivity. By extension, $l_{00}$ denotes the labor supply of productive countries that were already productive in the previous period, and $l_{-10}$ is the labor supply of participating productive countries that were excluded from financial markets in the previous period and that have just reentered the financial markets. Recall that the beginning-of-period wealth of these countries will also be assumed to be null: $B_{-1}=0$. The budget constraint (2) implies:

$$
l_{k 0}=u^{\prime-1}(1)-B_{k}+q B_{0}, k=-1,0, \ldots, D-1 .
$$

Remark 1 (Notation) To lighten the notation, in the remainder of the article we consistently employ the notation introduced in this section. For a variable $x, x_{k}$ is the quantity associated with a country that is unproductive for $k=1, \ldots, D-1$ periods, while $x_{k 0}$ denotes the quantity for a productive country that was unproductive for the $k=-1,0, \ldots, D-1$ previous periods. For instance, $x_{20}$ concerns a productive country that was unproductive in the two previous periods. The quantity associated with a productive country that was already productive in the previous period is $x_{00}$, while $x_{-10}$ refers to a productive country that was excluded. When the past status 
has no influence for a productive country - for instance in the case of consumption level - we simply use the notation $x_{0}$.

Furthermore, to distinguish between default and no-default quantities, we will use the superscripts $d$ and $n$ for default and no-default variables, respectively. Note that since consumption levels are identical in both equilibria, we will not use superscript.

We now turn to the analysis of the two possible equilibria.

\subsection{Default equilibrium}

\subsubsection{Characterization}

The default equilibrium features a finite number of periods to default $D$, stating that countries default after $D$ consecutive unproductive periods. The following proposition characterizes the default equilibrium.

Proposition 2 (Default equilibrium) In a default equilibrium,

1. The wealth two periods before default is higher than the unproductive threshold: $B_{D-2}^{d} \geq$ $\bar{B}^{u}$.

2. The wealth one period before default is equal to the productive threshold: $B_{D-1}^{d}=\bar{B}^{p}$.

The two items in Proposition 2 present the necessary conditions for the existence of a default

and a non-default equilibrium. Item 1 states that the wealth decreases and remains above $\bar{B}^{u}$, until the period preceding default. At that last period $(k=D-1)$, as stated in Item 2 , the wealth jumps downward to the negative level $\bar{B}^{p}<\bar{B}^{u}<0$, which implies that the country will default if it remains unproductive in the following period. The wealth $\bar{B}^{p}$ corresponds to the maximal debt level a country can borrow in period $D-1$. Should it borrow more than this amount, this would imply default in all states of the world in the following period and hence a null asset price. The country cannot borrow less than $\bar{B}^{p}$, since no wealth in the open set $\left(\bar{B}^{p}, \bar{B}^{u}\right)$ is optimal (Proposition 1). 
One of the implications of Proposition 2 is that the first-order conditions for asset choices in the default equilibrium can be expressed as follows:

$$
\begin{aligned}
q & =\beta\left(\alpha+(1-\alpha) u^{\prime}\left(c_{1}\right)\right), \\
q u^{\prime}\left(c_{k}\right) & =\beta\left(1-\rho+\rho u^{\prime}\left(c_{k+1}\right)\right), \quad k=1, \ldots, D-1, \\
q u^{\prime}\left(c_{D-2}\right) & \geq \beta\left(1-\rho+\rho u^{\prime}\left(c_{D-1}\right)\right), \\
q u^{\prime}\left(c_{D-1}\right) & >\beta .
\end{aligned}
$$

The other implication of Proposition 2 is to enable us to compute the countries' welfare, as a function of their idiosyncratic history. Consistently with our previous notation, we denote by $V_{k}^{d}$ the intertemporal welfare of a country participating in financial markets and unproductive for $k=1, \ldots, D$ periods, while $V_{k 0}^{d}$ denotes the intertemporal welfare of a productive country participating in financial markets, which was productive in the $k=-1, \ldots, D-1$ previous periods. Using this notation, countries' utilities are defined through the following recursion:

$$
\begin{aligned}
& V_{k 0}^{d}=V_{0}^{d}+B_{k}^{d}, k=-1, \ldots D-1, \\
& V_{0}^{d}=u\left(c_{0}\right)-c_{0}-q B_{0}^{d}+\beta\left(\alpha V_{0}^{d}+B_{0}^{d}+(1-\alpha) V_{1}^{d}\right), \\
& V_{k}^{d}=u\left(c_{k}\right)-\bar{l}+\beta\left((1-\rho)\left(V_{0}^{d}+B_{k}^{d}\right)+\rho V_{k+1}^{d}\right), k=1, \ldots, D-1 .
\end{aligned}
$$

Equation (20) takes advantage of the linearity of $V_{k 0}^{d}$ in asset choice to express productive utilities as a function of $V_{0}^{d}$ defined in $(21)$ - where we recall that $c_{0}=u^{\prime-1}(1)$. Equation (22) defines unproductive utilities (before default).

Using equations (21)-(21), the equations characterizing that countries default after $D$ consecutive unproductive periods can be expressed as:

$$
V_{0}^{d}+B_{D-1}^{d}=V_{p}^{a} \text { and } V_{D}^{d}=V_{u}^{a}
$$

Finally, we express the aggregate asset demand. Denote by $n_{k}$ the population of participating countries that are unproductive for $k$ consecutive periods for $1 \leq k \leq D$. From transition probabilities, we can state that $n_{k}=\rho^{k}(1-\alpha) n_{0}$ for $k=1, \ldots, D-1$, where $n_{0}$ denotes the mass of productive countries participating in financial markets. In the interests of conciseness, 
the explicit expression of these population shares is shown in Appendix A. Using this notation, the aggregate asset demand, denoted by $B_{a g g}^{d}$, can be expressed as follows:

$$
B_{\text {agg }}^{d}=\sum_{k=0}^{D-2} n_{k} B_{k}^{d}+(1-\rho) n_{D-1} B_{D-1}^{d} .
$$

\subsubsection{Existence conditions for partial equilibrium}

For a given asset price $q$, the default equilibrium can be computed using equations (16)-(23), and a detailed account of equilibrium computation can be found in Appendix C.1. Two sets of conditions need to be verified. First, participation constraints must hold. Participating countries must be better off participating than in autarky, which implies:

$$
V_{k}^{d,(D)} \geq V_{u}^{a}, 1 \leq k<D
$$

the conditions for productive countries holding by construction (equations (20) and (23) with decreasing $\left.\left(B_{k}\right)_{1 \leq k \leq D}\right)$. Second, the absence of a profitable deviation has to be checked. Countries that are unproductive for exactly $D$ consecutive periods should be worse off, either (i) by postponing the default by one period; or (ii) by not defaulting and opting for $\bar{B}^{u}$. Condition (i) states that the country unproductive for $D$ periods should not pay back its debt and default one period later. This means that the default horizon cannot be $D+1 .{ }^{10}$ Given that consumption levels are independent of $D$ (and determined by the price level and model parameters - see Euler equations (16)-(19)), this condition is in our tractable set-up equivalent to:

$$
V_{0}^{d,(D)} \geq V_{0}^{d,(D+1)}
$$

Condition (ii) states that the country unproductive for $D$ periods does not find it optimal to choose the continuation equilibrium (through the debt level $\bar{B}^{u}$ ) and not to default. Again since the consumption path only depends on the asset price $q$ through Euler equations (that are similar in the continuation and default equilibria), this condition is equivalent to:

$$
V_{0}^{d,(D)}>V_{0}^{n,(D)}
$$

\footnotetext{
${ }^{10}$ We provide a finite upper bound on the maximal feasible $D$ in Lemma 7 of Appendix C.1.
} 
stating that a productive country should opt for the default path rather than the continuation path.

\subsection{No-default equilibrium}

\subsubsection{Characterization}

The no-default equilibrium features an endogenous credit limit, which is determined by the participation constraint of unproductive countries, and which is reached in a finite number of periods that we denote by $T$. The following proposition characterizes the no-default equilibrium.

Proposition 3 (No-default equilibrium) The no-default equilibrium is characterized by a number of periods $0<T$, after which the wealth remains equal to the unproductive threshold: $B_{k}^{n}=\bar{B}^{u}$ for all $k \geq T$.

Proposition 3 states that in the no-default equilibrium, the wealth of unproductive countries decreases but remains above $\bar{B}^{u}$. Since $\bar{B}^{p}<\bar{B}^{u}<0$, any asset choice below $\bar{B}^{u}$ would imply default.

The characterization of the no-default equilibrium shares a number of common features with the default equilibrium. First, Euler equations can be written as follows:

$$
\begin{aligned}
q & =\beta\left(\alpha+(1-\alpha) u^{\prime}\left(c_{1}\right)\right), \\
q u^{\prime}\left(c_{k}\right) & =\beta\left(1-\rho+\rho u^{\prime}\left(c_{k+1}\right)\right), \quad k=1, \ldots, T-2, \\
q u^{\prime}\left(c_{k}\right) & >\beta\left(1-\rho+\rho u^{\prime}\left(c_{k+1}\right)\right), \quad k \geq T-1,
\end{aligned}
$$

which are very similar - except the $T$ - to Euler equations (16)-(17) of the default equilibrium. We can also easily compute utilities, which are denoted by $\left(V_{k}^{n}\right)_{k=0, \ldots, T}$, as follows:

$$
\begin{aligned}
& V_{0}^{n}=u\left(c_{0}\right)-c_{0}-q B_{0}^{n}+\beta\left(\alpha V_{0}^{n}+B_{0}^{n}+(1-\alpha) V_{1}^{n}\right), \\
& V_{k}^{n}=u\left(c_{k}\right)-\bar{l}+\beta\left((1-\rho)\left(V_{0}^{n}+B_{k}^{n}\right)+\rho V_{k+1}^{n}\right), k=1, \ldots, T-1 .
\end{aligned}
$$

A noticeable difference is that default conditions (23) are obviously not present. The wealth level $B_{T}=\bar{B}^{u}$ is determined by the fact that the country faces a binding participation constraint 
when unproductive after $T$ consecutive unproductive periods. Formally, the asset choice $B_{T}$ is determined by the following equation:

$$
V_{T}^{n}=V_{u}^{a}=u\left(\bar{l}+(1-q) B_{T}^{n}\right)-\bar{l}+\beta\left((1-\rho)\left(V_{0}^{n}+B_{T}^{n}\right)+\rho V_{u}^{a}\right) .
$$

The asset holding $B_{T}^{n}$ corresponds to the maximal amount of debt that a country can issue without defaulting. By committing not to default, unproductive countries can issue debt a price $q$ (and not $q(1-\rho)$ in case of default). Compared to autarky, such countries have the same utility level but experience a lower periodic consumption ( since $\bar{l}+(1-q) B_{T}^{n}<\bar{l}$ ) but a larger continuation utility if becoming productive $\left(V_{0}^{n}+B_{T}^{n}>V_{p}^{a}\right)$.

Finally, we express the aggregate asset demand in the no-default equilibrium. Observe that countries remaining unproductive after $T$ periods never default and all hold the same asset quantity $B_{T}^{n}$, such that the aggregate asset demand of those countries is $B_{T}^{n} n_{T} \sum_{k=0}^{\infty} \rho^{k}=$ $B_{T}^{n} n_{T} /(1-\rho)$. We deduce the aggregate asset demand, denoted by $B_{a g g}^{n}$, which can be expressed as follows:

$$
B_{\text {agg }}^{n}=\sum_{k=0}^{T-1} n_{k} B_{k}^{n}+B_{T}^{n} \frac{n_{T}}{1-\rho}
$$

\subsubsection{Existence conditions for partial equilibrium}

Similarly to the default case, the no-default equilibrium can be computed using equations (28)-(33), and we provide in Appendix C.2 a detailed account of the computation. Again, two sets of conditions need to be verified. First, participation conditions must hold, which implies:

$$
\begin{aligned}
V_{k}^{n,(T)} & \geq V_{u}^{a}, 1 \leq k<D, \\
V_{0}^{n,(T)}+B_{T}^{n} & \geq V_{p}^{a} .
\end{aligned}
$$

Second, the country unproductive for the last consecutive $T$ periods should prefer neither to postpone hitting the participation constraint by one period nor to default and opt for $\bar{B}^{p}$. 
Similarly to equations (26) and (27), the conditions for the no-default-equilibrium are:

$$
\begin{aligned}
& V_{0}^{n,(T)} \geq V_{0}^{n,(T+1)}, \\
& V_{0}^{n,(T)}>V_{0}^{d,(T)} .
\end{aligned}
$$

\section{General equilibrium and multiplicity}

So far, our analysis has focused on partial equilibrium - i.e., on countries' optimal strategies for a given asset price. We now turn to the general equilibrium analysis.

The derivation of the general equilibrium relies on Sections C.1 and C.2. For given asset price $q$, we explained in Section 3 how to select the relevant equilibrium structure. Once an equilibrium has been selected, we can deduce the aggregate asset demand from equation (24) or (34). We can therefore construct a mapping from asset price to aggregate asset demand, denoted by $q \mapsto B_{a g g}(q)$.

Computing the general equilibrium consists then in finding the asset price $q$, such that the financial market clears. The financial market clearing condition (9) becomes:

$$
B_{\text {agg }}(q)+B^{\text {out }}=0
$$

The general equilibrium finally corresponds to the asset price $q$ such that the financial market clears and equation (39) holds.

\subsection{A numerical illustration}

Our framework can generate general equilibrium multiplicity, which stems from a non-monotonic net aggregate saving function. This section presents a simple numerical example, to illustrate the intuition driving this property. We take advantage of this numerical example to discuss the effect of interest rates on default decisions, and the economic relevance of equilibrium multiplicity in Section 4.2. An additional interest of this section is to describe on a simple example the two possible equilibria that can be featured in our economy, the default and no-default equilibria.

To simplify the discussion of the effects, we assume that the probability to reenter the 
financial market after default is set to $0: \theta=0$. To maintain a constant size of the participating population, it is further assumed that when a country defaults, a new country "enters" into the economy with zero wealth. The probability that the country is initially productive is $n^{p}$ and not productive $1-n^{p}$. As a consequence, both the size and the structure of the participating population are constant. The gain of this assumption is that the interest rate does not affect the autarky welfare, since defaulting countries are excluded forever. This simplifies the interpretation of the results. ${ }^{11}$

Our calibration features $\sigma=2, \beta=0.96, \bar{l}=0.4, \alpha=0.9, \rho=0.15$. For a given outside liquidity $\left(B^{\text {out }}=0.3\right)$, this economy generates the simultaneous existence of two default equilibria (for $D=4$ and 5), corresponding to two different liquidity prices. For a higher outside liquidity $\left(B^{\text {out }}=1.5\right)$, there is a unique equilibrium, with no-default and $T=3$.

Figure 1 plots the relationship between the real interest rate $r=\frac{1}{q}-1$ and aggregate asset demand. ${ }^{12}$ The real interest rate is reported on the y-axis and the net excess supply on the x-axis. Figure 1 thus plots the inverse demand function on financial markets. The general equilibrium is determined by the vertical line in 0 .

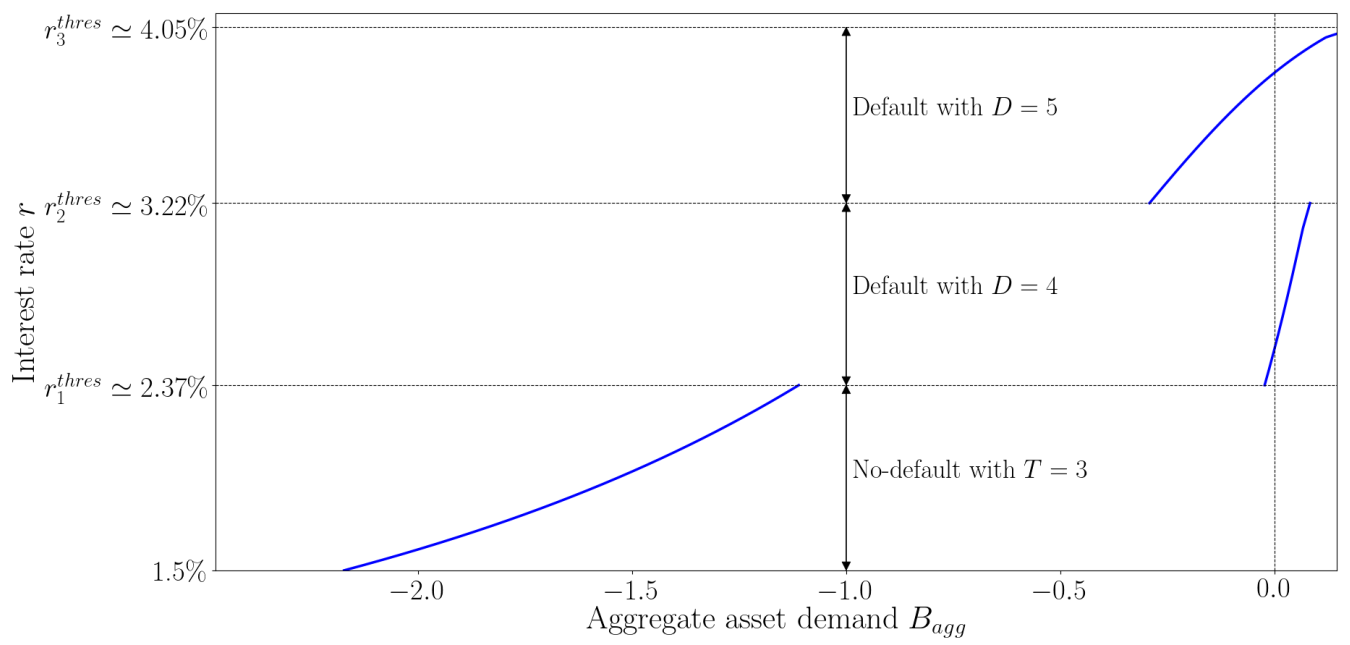

Figure 1: Interest rate (y-axis) in $\%$ as a function of the net total demand (x-axis)

\footnotetext{
${ }^{11}$ Another theoretical reason for this assumption is that uniqueness in partial equilibrium is not guaranteed in presence of reentry (see Auclert and Rognlie, 2016, Proposition 10). Ruling out reentry ensures that multiplicity is not a partial equilibrium outcome, but a new general equilibrium one.

${ }^{12}$ Following Aiyagari (1994) and the heterogeneous-agent literature, we use the real interest rate $r$ instead of the price $q$ and we plot the inverse demand function.
} 
The aggregate asset demand exhibits two major discontinuities at the interest rates $r_{1}^{\text {thres }}=$ $2.370 \%$ and $r_{2}^{\text {thres }}=3.225 \%$ (as well as other ones of smaller magnitudes, for instance for $r_{3}^{\text {thres }}=4.051 \%$ as can be seen in Figure 1). For $1 \%<r<r_{1}^{\text {thres }}$, the equilibrium is a nodefault equilibrium. Countries reach the endogenous credit constraint after $T=3$ consecutive unproductive periods. For $r_{1}^{\text {thres }}<r<r_{2}^{\text {thres }}$, the equilibrium is such that countries default after $D=4$ unproductive periods. Finally, for $r_{2}^{\text {thres }}<r<4 \%$ the countries default after $D=5$ periods being unproductive. For $r>4 \%$, the default equilibrium still prevails and the number of periods before default $D$ increases as $r$ tends toward $1 / \beta-1=4.17 \%$. The key mechanism for equilibrium multiplicity is the discontinuity of the asset demand implied by the change in the optimal default strategies at the two threshold $r_{1}^{\text {thres }}$ and $r_{2}^{\text {thres }}$ (reflected by the succession of different equilibria).

To understand more deeply the mechanisms, we now focus on the asset demands around the interest rates for which the default strategy changes. For $r=r_{1}^{\text {thres }}-\varepsilon$, (with $\varepsilon$ small, which we have chosen equal to $10^{-6}$ ), the equilibrium is a no-default equilibrium with $T=3$. For $r=r_{1}^{\text {thres }}+\varepsilon$, the equilibrium is a default equilibrium with $D=4$. Figure 2 plots in red the asset demands $B_{k}$ for $k=1, \ldots, 4$ of unproductive countries for the default economy, and in blue the $B_{k}, k=1, \ldots, 3$ in the no-default equilibrium. When the interest rate increases from

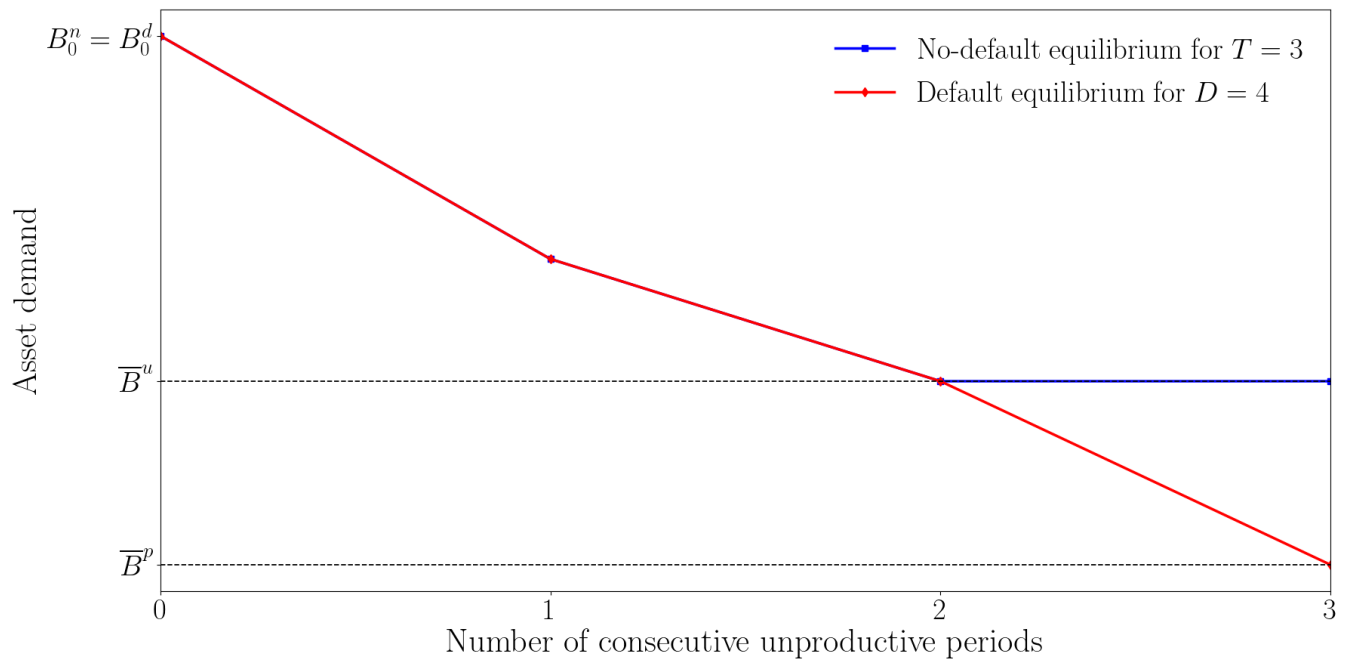

Figure 2: Asset demand path $\left(B_{k}\right)_{k}$ around $r_{1}^{\text {thres }}$.

$r_{1}^{\text {thres }}-\varepsilon$ to $r_{1}^{\text {thres }}+\varepsilon$, countries switch from the no-default to the default equilibrium. Two 
effects are at stake. First, countries save a higher amount (or borrow less) because of a higher remuneration of savings. Second, countries pay a higher interest rate on their borrowing (i.e., sell their debt at a lower price) and have a higher incentive to default when unproductive. For this last reason, the endogenous credit constraint in the no-default equilibrium is tighter when the interest rate increases. We find that the endogenous credit constraint $\bar{B}^{u}$ increases (i.e, becomes tighter) from -4.6 to -2.3 when the interest increases from $1 \%$ to $2.3 \%$. If the interest rate increases above $r_{1}^{\text {thres }}$, the country becomes better-off defaulting to relax this constraint. In case of default, borrowing increases sharply after 4 unproductive periods and hits the other endogenous credit limit $\bar{B}^{p}$, as can be seen in Figure 2 .

When the interest rate increases further (beyond $r_{1}^{\text {thres }}+\varepsilon$ ), countries first stay at the default equilibrium with $D=4$, and the aggregate asset demands of all countries increase. Indeed, as the incentives to default increase when the interest rate increases, the endogenous borrowing limit $\bar{B}^{p}$ (for $D=4$ ) increases, contributing to shift upwards their asset demand.

When the interest rate increases even further from $r_{2}^{\text {thres }}-\varepsilon$ to $r_{2}^{\text {thres }}+\varepsilon$, the borrowing constraint is relaxed since the endogenous borrowing limit $\bar{B}^{p}$ for $D=5$ becomes reachable (in the sense that the default equilibrium with $D=5$ exists). Similarly to Figure 2, Figure 3 plots the two asset demand paths $\left(B_{k}\right)_{k=0, \ldots, D}$ for $D=4$ and $D=5$ corresponding to the interest rates $r_{2}^{\text {thres }}-\varepsilon$ and $r_{2}^{\text {thres }}+\varepsilon$, respectively. When the interest rate increases toward $1 / \beta-1$, and

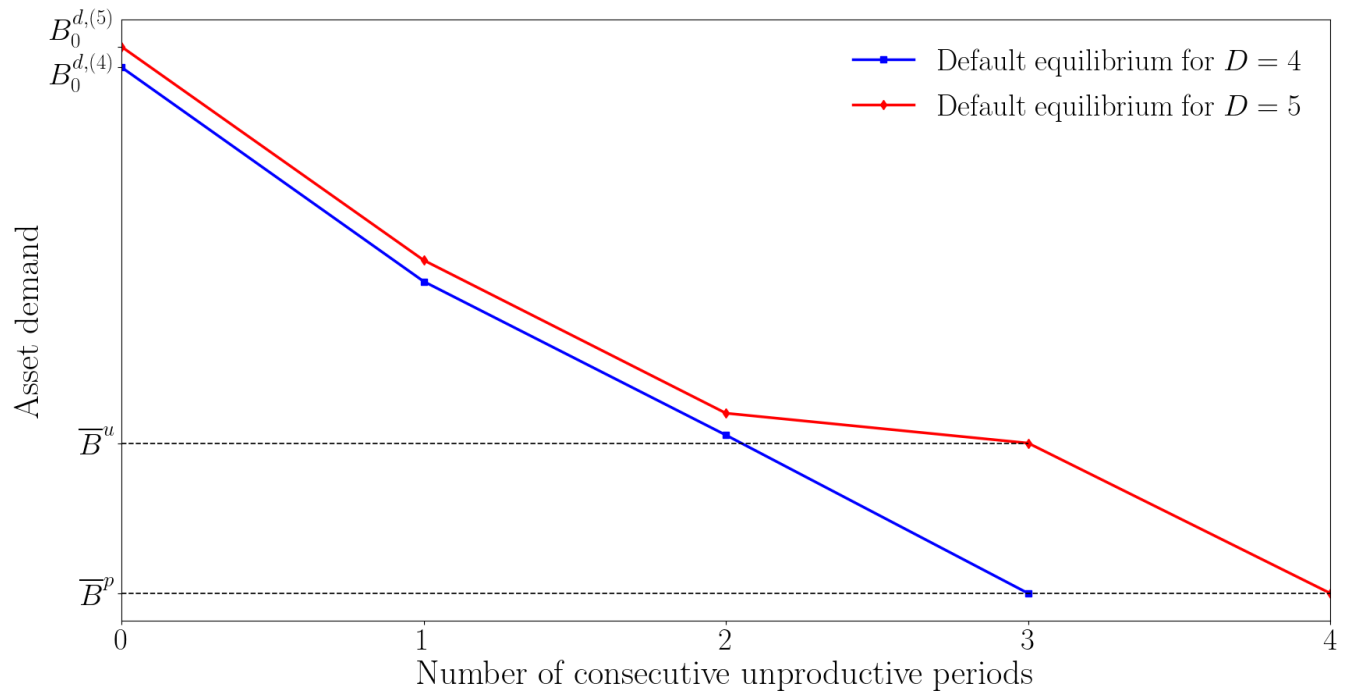

Figure 3: Policy rules around $r_{2}^{\text {thres }}$. 
beyond $r_{2}^{\text {thres }}$, countries demand a higher asset quantity to smooth consumption and $D$ increases toward infinity - with other discontinuities, as for instance for $r_{3}^{\text {thres }}$.

The discontinuity in aggregate asset demands comes from the combined effect of an extensive variation in asset demands (the change in $D$ implying a larger number of countries participating in financial markets) and an intensive variation (related to the variation of each $B_{k}$ ). First, when the default equilibrium switches from $D=4$ to $D=5$ (for the interest rate $r_{2}^{\text {thres}}$ ), the extensive margin makes a larger share of countries participate in financial markets, but the intensive margin makes each country borrow less and express a higher asset demand. The extensive margin dominates, inducing a greater aggregate borrowing and a smaller aggregate asset demand.

Second, when countries switch from the no-default to the default equilibrium (for the interest rate $r_{1}^{\text {thres }}$ ), both the extensive and intensive margins contribute to a reduction in total borrowing - and a higher aggregate asset demand. Indeed, when switching to a default equilibrium a large share of countries becomes excluded from financial markets, implying that the extensive margin in this case implies fewer countries participating in financial markets. This generates a sizable increase in aggregate asset demand. ${ }^{13}$

It is insightful to compare the non-continuous aggregate savings to the ones obtained in an heterogeneous-agent model with exogenous or natural borrowing constraints, as in the seminal work of Aiyagari (1994), for instance. In such economies, aggregate asset demand is increasing and continuous, ensuring equilibrium existence and uniqueness, which is not the case in our framework (Açikgöz, 2018; Light, 2020). Finally, the equilibrium multiplicity we identify in this section differs from the one analyzed by Cole and Kehoe (2000), as it relies on a general equilibrium effect.

\subsection{Economic relevance of equilibrium multiplicity mechanisms}

The economic relevance of the mechanisms for equilibrium multiplicity that we have identified in this section is admittedly hard to assess. A large share of the world savings comes from developed

\footnotetext{
${ }^{13}$ Note that, as can be seen from Figure 1, this jump in aggregate asset demand implies that no general equilibrium but autarky would exist if outside liquidity $B^{\text {out }}$ were slightly larger.
} 
countries, which are not concerned by sovereign default as mentioned in the introduction. The experience of a default of a large (in terms of aggregate savings) country would be a test for the existence of multiple equilibria. A less dramatic implication of the current example is that small changes in the world interest rate, whatever the reason, can generate a drastic change in default strategies, changing from no-default to default equilibrium.

As a final comment, changes in the interest rate envisioned in the current section are permanent changes, as they affect the whole saving strategy. An unexpected increase in the world interest rate would raise default incentives, before countries adjust their self-insurance saving. The analysis of aggregate shocks in this setting is left for future work.

\section{Constrained-efficiency and the provision of outside liquidity}

We now show that the default and no-default equilibria are not constrained-efficient, as the social value of liquidity is not fully reflected in prices. We then provide simple institutional settings which can increase welfare by providing additional liquidity to the world economy. The liquidity remains indeed insufficient for constrained-efficiency, due to market incompleteness. Davila, Hong, Krusell, and Rios-Rull (2012) show that the market equilibrium is not constrainedefficient in an incomplete-market model with borrowing constraint, and no default. One can thus see our results as an extension to an economy with default. To show this formally, we follow the methodology of Davila, Hong, Krusell, and Rios-Rull (2012), who define a relevant notion of constrained-efficiency in an incomplete insurance-market environment without default. We extend this to an economy with default, imposing an additional participation constraint on the quasi-planner. ${ }^{14}$ The idea is to solve for the allocation, when a quasi-planner internalizes the effect of liquidity choices on interest rates (countries are no longer price-takers). This analysis not only compares steady-state welfare levels, but also considers the cost of transition to different steady-states. ${ }^{15}$

In general, the constraint-efficient allocation can deliver two types of equilibria. In the

\footnotetext{
${ }^{14}$ The term quasi-planner refers to a planner maximizing social welfare with country-specific budget constraints as in Veracierto (2008) in a different environment, for instance.

${ }^{15}$ Comparing steady-state welfare is indeed not a consistent way to rank allocations, as it does not properly consider consumption smoothing. See LeGrand and Ragot (2020) for a discussion and additional references.
} 
first one, discussed in Section 5.1, the allocation features equilibrium default. This equilibrium structure is the relevant one for our quantitative example, presented in Section 5.4. In the second type of equilibria, no country defaults. For the sake of generality, we derive the structure of this equilibrium in Appendix E.

\subsection{Constrained-efficiency in the economy with default}

In this section, we assume that the constraint-efficient allocation features equilibrium default. The quasi-planner can choose how much each country - which is not in the default state can save, consume, and work, but it cannot transfer resources across countries (country-specific budget constraints must hold in the absence of any transfer) and cannot prevent countries from defaulting (countries' participation constraints must also hold). The quasi-planner also internalizes the financial market clearing condition and thus necessary transversality conditions for country saving not to diverge. The optimal allocation of the quasi-planner thus defines the constrained-efficient allocation when the pecuniary externality is internalized.

The constrained-efficient allocation of the quasi-planner is summarized in the next proposition. The proof of the proposition is provided in Appendix D.

Proposition 4 (Constrained-efficient allocation in presence of default) The constrainedefficient allocation in a default equilibrium is characterized by a default horizon $\tilde{D}$ and allocations $\tilde{c}_{k}^{d}=u^{\prime-1}(1)$ for $k=0, \ldots, \tilde{D}-1$.

When the constrained-efficient equilibrium features equilibrium default, the quasi-planner

chooses that default occurs after $\tilde{D}$ periods in unproductive status. The optimal outcome is then to maximize the safe asset quantity and to implement full risk-sharing among participating countries. This increases the welfare of participating countries, and therefore reduces the default incentives. As a direct consequence, the constrained-efficient allocation in general differs from the market allocation characterized in Section 3. To see this, observe that $\tilde{c}_{k}^{d}=u^{\prime-1}(1)$ in the market economy implies $q=\beta$. However, in this case, there is no reason for the saving decisions to satisfy the financial market clearing condition. Since the quasi-planner internalizes the financial 
market clearing condition, it distorts individual saving decisions to reach full risk-sharing, while allowing financial markets to clear.

\subsection{Increasing risk-sharing: Designing an International Financial Institution (IFI)}

As the market equilibrium is not constrained-efficient, we present an institutional arrangement to increase risk-sharing through outside liquidity provision. This arrangement involves an IFI that issues world liquidity and implements full risk-sharing among its members, as in the constrainedefficient allocations. We first provide the commitment devices generating full risk-sharing, and then discuss it below.

The environment is the same as in Section 2 (we keep the same notation). The IFI issues one-period, risk-free debt financed by the contributions of member states. The IFI transfers are forbidden from being contingent on a country's productive status. Otherwise, the IFI could implement the first-best allocation by completing the market. The IFI has therefore no comparative advantage over financial markets. ${ }^{16}$ We make here the following assumptions regarding the IFI.

1. The IFI can issue debt and is financed solely by the contributions of member countries.

2. Countries can freely choose to belong to the IFI and can always choose to opt out.

3. Contributing countries agree not to transact with countries not contributing to the IFI.

4. Contributing countries can commit to hold a maximum amount of liquidity.

First, the IFI budget is financed only by the contributions of countries. Second, countries can decide whether to participate in the IFI or not. The participation decision is sovereign. Third, contributing countries agree, when joining the IFI, not to transact with non-contributing countries. Otherwise, countries would have no incentive to pay their contribution to the IFI,

\footnotetext{
${ }^{16}$ One could argue that the ability to lend to countries in crisis against some credible commitment from these countries (a program) is a comparative advantage for certain international institutions, such as the IMF. This comparative lending advantage helps complete the market. We do not consider this role here, but instead focus solely on the supply of liquidity.
} 
as they could benefit from outside liquidity (and pay the world interest rate on any safe asset through the absence of arbitrage) without paying any contributory costs.

We denote by $F^{\prime}$ the debt newly issued by the IFI at price $q$ in a given period, while $F$ is the amount the IFI repays. Note that the IFI pays the world risk-free interest rate due to the absence of arbitrage. The measure of countries participating in the IFI is denoted by $m_{p}$. Countries participating in the IFI pay $\tau$. Using this notation, the IFI budget constraint is:

$$
F=q F^{\prime}+m_{p} \tau
$$

The world financial market clearing condition can now be expressed as:

$$
B_{\text {agg }}=F^{\prime}
$$

where $B_{a g g}$ is the aggregate savings of equations (24) and (34). Finally, the budget constraints of countries are the same as (13)-(15), except that countries additionally contribute to the IFI by an amount $\tau$.

As shown in Proposition 5 below, full-risk sharing can be implemented for all countries participating in the IFI. Indeed, to implement full risk-sharing, the IFI chooses the volume of its debt such that the equilibrium price of liquidity is $q=\beta$. In this case, the Euler equations of participating countries imply that their marginal utility of consumption is 1 . At this price, however, all productive countries would decide to work a lot to buy a huge amount of liquidity to self-insure against fluctuating income. Indeed, there is no opportunity cost to save for consumption smoothing, and expected uninsurable shocks always generate an additional incentive to save. This outcome is the standard result of Bewley (1983) about saving decisions with precautionary motives. But this deviation would prevent the existence of the equilibrium, as the IFI would have to issue a huge amount of liquidity. To prevent this deviation, the IFI must be able to limit the savings of countries participating in the risk-sharing arrangement. With this limited amount of liquidity, one can check that the country is still willing to join the risk-sharing arrangement. This explains why Assumption 4 is needed for equilibrium existence.

Proposition 5 (Equilibria with IFI) We consider the introduction of an IFI, where assump- 
tions 1 to 4 hold. For finite D, there exists a value of $F$ such that the marginal utility of consumption of all participating countries is 1 among countries participating in the IFI, and risk-sharing is thus perfect.

The proof can be found in Appendix F, where we provide existence conditions. The equilibrium quantity $F$ is determined to guarantee that the asset price is $q=\beta$. In this equilibrium, productive countries save to participate in the risk-sharing arrangement, and unproductive countries dis-save until countries optimally choose to default. Even in the presence of Assumption 4 above, the proposition remains silent regarding existence. Indeed, existence is not guaranteed in the general case, as the contribution to the IFI needed to balance the IFI budget constraint may be too high for countries to be willing to join the risk-sharing arrangement, even when in autarky. Instead, we provide below a numerical example to show existence and the properties of such an IFI in a quantitatively relevant environment. The IFI can be seen as a pure financial actor targeting the proper interest rate using the size of its balance sheet in this non-Ricardian environment.

Assumption 4 can be relaxed, such that we preserve only Assumptions 1 to 3. In this case, the IFI cannot implement full-risk sharing among its members. In such a case, the IFI will issue an amount of liquidity slightly lower than the optimal level $F$, such as to implement a price slightly higher than $\beta$. The allocation with IFI can thus be made arbitrarily close to the full risk-sharing allocation of Proposition 5. It is more difficult to relax Assumption 3. Indeed, countries out of the default state could choose not to contribute to the fund, while still benefiting from the world liquidity. This would impair the IFI existence.

\subsection{Comparison with Special Drawing Rights}

This IFI is obviously reminiscent of the IMF with its Special Drawing Rights, which are international stores of value. SDRs are reserve assets and have been issued by the IMF since 1970, with the explicit goal of reducing the world liquidity shortage (see Williamson, 2009 for a summary of the history of the introduction of SDRs). A difference between the IFI introduced in this section and SDRs is that the interest rate on assets issued by the IFI is a yearly interest rate 
comparable to the one on sovereign debts, whereas the remuneration of SDRs is an average of short-term (3 months) interest rates on a basket of currencies. This remuneration is thus closer to the one of monetary markets. ${ }^{17}$

\subsection{A numerical example}

To provide further insights, we now perform a quantitative exercise to investigate our equilibrium structure and to analyze the size of the IFI. To calibrate the model, we use both the literature on disaster events in macro and on sovereign default. The logic of the calibration is to assume that countries borrow when they face a disaster (i.e., the country is in the unproductive state) and default when they stay in the disaster state for two periods. We thus choose parameter values to obtain a default equilibrium with $D=2$, and to match standard moments about the probability to default and recovery rates.

The curvature of the utility function is set to $\sigma=2$, as in Arellano (2008), and the discount factor is set to the standard value of $\beta=0.96$. We set the probability of remaining productive to $96.5 \%$ such that the probability of moving from a productive to unproductive state is $3.5 \%$. This is equal to the annual probability of entering into a disaster state, as found by Barro and Ursúa (2012). The probability to remain in the disaster state is set to $2 \%$, which is the average default probability of borrowing countries as shown by Tomz and Wright (2013), who find an unconditional probability of default of debtors between $1.8 \%$ and $2.2 \%$. The probability to reenter the economy after default is set to $\theta=15 \%$ such that the average number of years in the default state is 7 years, as explained by Tomz and Wright (2013). The last parameter to calibrate is the fall of productive capacity in the disaster state. We set $\bar{l}=0.3$ to obtain $D=2$ as a target. An additional implication of this choice is that the amount of borrowing is $37 \%$ of potential GDP. This amount is in the high range provided by Tomz and Wright (2013), which is a face value between $15 \%$ and $40 \%$. The calibration is summarized in Table 1 .

We now compute the optimal size of the IFI that implements full risk-sharing among its members, with the assumptions of Section 5.2. All countries participating in financial markets

\footnotetext{
${ }^{17}$ The weekly interest rates on SDRs are provided at http://www.imf.org/external/np/fin/data/sdr_ir. aspx, together with the explicit interest rate formula. The current level of outstanding IMF SDRs amounted to less than $0.3 \%$ of world GDP in 2016 .
} 


\begin{tabular}{lll}
\hline Parameters & Values & Target and references \\
\hline $\begin{array}{ll}\text { Discount factor } \\
\text { Utility function }\end{array}$ & $\sigma=0.96$ & Interest rate of $4 \%$ \\
Persistence of good state & $\alpha=96.5 \%$ & $\begin{array}{l}\text { Arellano (2008) } \\
\text { (B.5\% disaster probability }\end{array}$ \\
Persistence of disaster & $\rho=2 \%$ & Unconditional default probability $2 \%$ \\
& & (Tomz and Wright, 2013) \\
Labor in disaster state & $\bar{l}=0.3$ & $D=2$ \\
& & \\
Prob. of reentering & $\theta=15 \%$ & (Tomz and Wright, 2013) \\
\hline
\end{tabular}

Table 1: Calibration

for $D=2$, either productive or not, enjoy the same consumption, equal to 1 . There is thus full risk-sharing for countries participating in the financial markets. This value of $D$ is attained for a size of the IFI equal to $37.7 \%$ of world GDP. The average contribution of a country to the IFI is equal to approximately $\tau=1.52 \%$ of its own average GDP. We find that the welfare gain of introducing the IFI represents for countries an average increase in consumption of $1.0 \%$ compared to the consumption in the market economy. This gain is relatively small but significant. ${ }^{18}$

As mentioned above, in the absence of Assumption 4 of Section 5.2, this allocation cannot be exactly achieved, as countries participating in the fund would save an unbounded amount when $q=\beta$. However, the allocation with the fund can be made arbitrarily close to the full insurance economy implementing a size of a fund slightly lower than its optimal value to obtain $q=\beta+\varepsilon$ (with $\varepsilon$ small but positive).

Admittedly, this exercise is a first investigation of the quantitative implication of optimal policies in equilibrium with sovereign default, as additional effects should be introduced. We

\footnotetext{
${ }^{18}$ We compute the increase in consumption in the market economy for all countries to have the same aggregate welfare as the one of the IFI allocation. Doing so, we keep constant the policy rules in the market economy (and thus the default decision). This is the standard computation of consumption equivalent to compare allocations in heterogeneous-agent models.
} 
list possible extensions in the next section and provide paths for future work in the Conclusion.

\section{Extensions}

Enriching the cost of default. Following Arellano (2008), a first extension to the cost of default is to assume that countries in autarky only have access to a less efficient production technology, through which 1 unit of labor is transformed into only $\varphi \in(0,1]$ units of consumption. The present model corresponds to the case where $\varphi=1$. The second extension follows Arellano, Bai, and Bocola (2019) and Arellano, Bai, and Mihalache (2020) and assumes that the debt repayment in cases of default is exogenous and equal to $\underline{B}<0$. The recovery rate is therefore endogenous and amounts to $\underline{B} / B^{\prime}$, which depends on the asset choice $B^{\prime}$. Our specification corresponds to $\underline{B}=0$.

These specifications have two main implications. First, the price schedule of equation (1) becomes:

$$
q\left(B^{\prime}, s\right)=q \times\left(1-\delta\left(B^{\prime}, s\right)+\delta\left(B^{\prime}, s\right) \frac{B}{B^{\prime}}\right) .
$$

Second, the value functions in autarky should account for the possibility to repay $\underline{B}$. More

precisely, expressions (4) and (5) depend on the beginning-of-period asset holding, denoted by $b$, and are:

$$
\begin{aligned}
& V_{p}^{a}(b)=\max _{l}(u(\varphi l+b)-l)+\beta \alpha\left(\theta V_{p}^{o}(0)+(1-\theta) V_{p}^{a}(0)\right)+\beta(1-\alpha) V_{u}^{a}(0), \\
& V_{u}^{a}(b)=u(\varphi \bar{l}+b)-\bar{l}+\beta(1-\rho)\left(\theta V_{p}^{o}(0)+(1-\theta) V_{p}^{a}(0)\right)+\beta \rho V_{u}^{a}(0) .
\end{aligned}
$$

The countries that have just defaulted and are paying the debt amount $\underline{B}$ are endowed with utility $V_{s}^{p}(\underline{B})(s=p, u)$, while countries that were already in autarky and have no asset holdings $(b=0)$ are endowed with utility $V_{s}^{p}(0)(s=p, u)$.

Our analysis should be consistently adapted and in particular, autarky utilities should now reflect the repayment $\underline{B}$. For instance, the definition of quantities $\bar{B}^{s} \in \mathbb{R} \cup\{-\infty\}, s=p, u$ in equation (8) should now be:

$$
\bar{B}^{s}=\min \left\{B \in \mathbb{R} \mid V_{s}^{c}(B) \geq V_{s}^{d}(\underline{B})\right\}, s=p, u .
$$


Besides this adaptation, our equilibrium structure would remain similar. Introducing these modifications only generates additional algebra to determine equilibrium strategies.

Considering market power: the role of a Hegemon. The analysis above has focused on the case where every country was a price-taker and had no market power. We can check that our qualitative results are robust to the introduction of a country having some market power in the world financial markets - such a country being often called the Hegemon. Indeed, some authors argue that this may be a relevant representation of the economy (see Eichengreen, 2011, or Farhi and Maggiori, 2018 or Bai, Kehoe, and Perri, 2019). We check in Appendix G that our main result, stating that an IFI improves welfare, is still qualitatively valid in this environment.

\section{Conclusion}

We provide a tractable model where sovereign default can be studied in general equilibrium. This model allows the derivation of positive and normative properties of the equilibrium structure implied by the endogenous quantity of the world safe asset. We find that welfare is increased by the introduction of an IFI that issues safe assets based on the voluntary contributions of member states. The qualitative results are robust to more general default costs or to the case where a country is large enough to wield some market power on the world financial markets.

The tractability of the framework would lead us to investigate several extensions. A first possibility would be to investigate the role and the benefits of long-term debt. Another possibility would be to add heterogeneous risk processes to explicitly model heterogeneity between emerging and developed countries. ${ }^{19}$ Indeed, developed countries rarely default. It could thus be interesting to construct equilibria where some countries endogenously stay at the endogenous credit constraint in the worst case (due to their idiosyncratic risks) whereas others choose to default. The current tractable framework can easily be extended in this direction. Investigating mechanisms to increase risk-sharing in such environments would then be possible.

\footnotetext{
${ }^{19}$ See for instance Bai, Kehoe, and Perri (2019) or Morelli, Ottonello, and Perez (2019) for a discussion of additional heterogeneity needed to capture international heterogeneity in the default decision.
} 


\section{References}

AçıKGÖz, O. (2018): "On the Existence and Uniqueness of Stationary Equilibrium in Bewley Economies with Production," Journal of Economic Theory, 173, 18-55.

Aguiar, M., And M. Amador (2015): "Chapter 11 - Sovereign Debt," in Handbook of International Economics, ed. by E. Helpman, K. Rogoff, and G. Gopinath, vol. 4 of Handbook of International Economics, chap. 11, pp. 647-687. Elsevier.

Aguiar, M., and G. Gopinath (2006): "Defaultable Debt, Interest Rates and the Current Account," Journal of International Economics, 69(1), 64-83.

Aiyagari, R. S. (1994): "Uninsured Idiosyncratic Risk and Aggregate Saving," Quarterly Journal of Economics, 109(3), 659-684.

Arellano, C. (2008): "Default Risk and Income Fluctuations in Emerging Economies," American Economic Review, 98(3), 690-712.

Arellano, C., Y. Bai, and L. Bocola (2019): "Sovereign Default Risk and Firm Heterogeneity," Working Paper, University of Rochester.

Arellano, C., Y. Bai, and S. Lizarazo (2017): "Sovereign Risk Contagion," Working Paper, University of Rochester.

Arellano, C., Y. Bai, and G. Mihalache (2020): "Monetary Policy and Sovereign Risk in Emerging Economies," Working Paper, University of Rochester.

Auclert, A., And M. Rognlie (2016): "Unique Equilibrium in the Eaton-Gersovitz Model of Sovereign Debt," Journal of Monetary Economics, 84, 134-146.

Azzimonti, M., E. De Francesco, and V. Quadrini (2014): "Financial Globalization, Inequality, and the Rising Public Debt," American Economic Review, 104(8), 2267-2302.

Bai, Y., P. Kehoe, and F. Perri (2019): "Financial Cycles," Working Paper, Federal Reserve Bank of Minneapolis.

Bai, Y., And J. Zhang (2010): "Solving the Feldstein-Horioka Puzzle With Financial Frictions," Econometrica, 78(2), 603-632.

Barro, R. J., J. Fernández-Villaverde, O. Levintal, and A. Mollerus (2016): "Safe Assets," NBER Working Paper 20652, National Bureau of Economic Research.

Barro, R. J., and J. F. Ursúa (2012): "Rare Macroeconomic Disaster," Annual Review of Economics, 4(1), 83-109.

Bewley, T. F. (1983): "A Difficulty with the Optimum Quantity of Money," Econometrica, 54(5), 1485-1504.

Bulow, J. I., And K. S. Rogoff (1989): "Sovereign Debt: Is to Forgive to Forget?," American Economic Review, 79(1), 43-50.

Caballero, R. J., and E. Farhi (2017): "The Safety Trap," Review of Economic Studies, $85(1), 223-274$.

Calvo, G. (1988): "Servicing the Public Debt: The Role of Expectations," American Economic Review, 4(78), 647-661. 
Challe, E., F. LeGrand, and X. Ragot (2013): "Incomplete Markets, Liquidation Risk and the Term Structure of Interest Rates," Journal of Economic Theory, 148(6), 2483-2519.

Chamberlain, G., and C. Wilson (2000): "Optimal Intertemporal Consumption Under Uncertainty," Review of Economic Dynamics, 6(3), 365-395.

Chatterjee, S., D. Corbae, M. Nakajima, and J.-V. Ríos-Rull (2007): “A Quantitative Theory of Unsecured Consumer Credit with Risk of Default," Econometrica, 75(6), 1525-1589.

Clarida, R. (1990): "International Lending and Borrowing in a Stochastic Stationary Equilibrium," International Economic Review, 31(3), 543-558.

Cladusen, A., and C. Strub (2020): "Reverse Calculus and Nested Optimization," Journal of Economic Theory, 187, 105019.

Cole, H., And T. Kehoe (2000): "Self-Fulfilling Debt Crises," Review of Economic Studies, $67,91-116$.

Davila, J., J. Hong, P. Krusell, and V. Rios-Rull (2012): "Constrained Efficiency in the Neoclassical Growth Model With Uninsurable Idiosyncratic Shocks," Econometrica, 80(6), $2431-2467$.

Dubey, P., J. Geanakoplos, and M. Shubik (2005): "Default and Punishment in General Equilibrium," Econometrica, 73(1), 1-37.

Eaton, J., And M. Gersovitz (1981): "Debt with Potential Repudiation: Theoretical and Empirical Analysis," Review of Economic Studies, 48(2), 289-309.

Eichengreen, B. (2011): Exorbitant Privilege: The Rise and Fall of the Dollar and the Future of the International Monetary System. Oxford University Press.

FARHi, E., And M. Maggiori (2018): "A Model of the International Monetary System," Quarterly Journal of Economics, 133(1), 295-355.

Feldman, M., and C. Gilles (1985): "An Expository Note on Individual Risk without Aggregate Uncertainty," Journal of Economic Theory, 35(1), 26-32.

Gorton, G., S. Lewellen, And A. Metrick (2012): "The Safe-Asset Share," American Economic Review, 102(3), 101-106.

Green, E. (1994): "Individual-Level Randomness in a Nonatomic Population," Working Paper, University of Minnesota.

Hall, R. E. (2016): "The Role of the Growth of Risk-Averse Wealth in the Decline of the Safe Real Interest Rate," NBER Working Paper 22196, National Bureau of Economic Research.

Hansen, G. D. (1985): "Indivisible Labor and the Business Cycle," Journal of Monetary Economics, 16(3), 309-327.

HAVRÁneK, T. (2015): "Measuring Intertemporal Substitution: The Importance of Method Choices and Selective Reporting," Journal of the European Economic Association, 13(6), 11801204.

He, Z., A. Krishnamurty, and K. Milbradt (2019): "A Model of Safe Asset Determination," American Economic Review, 109(4), 1230-1262. 
Lagos, R., And R. Wright (2005): "A Unified Framework for Monetary Theory and Policy Analysis," Journal of Political Economy, 113(3), 463-484.

LeGrand, F., And X. Ragot (2020): "Managing Inequality over the Business Cycle: Optimal Policies with Heterogeneous Agents and Aggregate Shocks," Working Paper, SciencesPo.

Light, B. (2020): "Uniqueness of Equilibrium in a Bewley-Aiyagari Model," Economic Theory, $173,435-450$.

Livshits, I., J. MacGee, And M. Tertilt (2007): "Consumer Bankruptcy: A Fresh Start," American Economic Review, 97(1), 402-418.

Lorenzoni, G., And I. Werning (2019): "Slow Moving Debt Crises," American Economic Review, 109(9), 3229-3263.

Mendoza, E., V. Quadrini, and J.-V. Rios-Rull (2009): "Financial Integration, Financial Development and Global Imbalances," Journal of Political Economy, 117(3), 371-416.

Morelli, J., P. Ottonello, and D. Perez (2019): "Global Banks and Systemic Debt Crises," Working Paper, New York University.

Rogerson, R. (1988): "Indivisible Labor, Lotteries and Equilibrium," Journal of Monetary Economics, 21(1), 3-16.

Scheinkman, J., and L. Weiss (1986): "Borrowing Constraints and Aggregate Economic Activity," Econometrica, 54(1), 23-45.

Stokey, N. L., R. E. J. Lucas, and E. C. Prescott (1989): Recursive Methods in Economic Dynamics. Harvard University Press.

Tomz, M., And M. L. J. Wright (2013): "Empirical Research on Sovereign Debt and Default," Annual Review of Economics, 5(1), 247-272.

Veracierto, M. (2008): "Firing Costs and Business Cycle Fluctuations," International Economic Review, 49(1), 1-39.

Williamson, J. (2009): "Understanding Special Drawing Rights (SDRs)," Policy Brief 09-11, Peterson Institute For International Economics.

Zhang, H. H. (1997): "Endogenous Borrowing Constraints with Incomplete Markets," Journal of Economic Theory, 52(5), 2187-2209. 


\section{Appendix}

\section{A Population shares}

Using the model set-up presented in Section 2.1, we deduce the following population shares:

$$
\begin{aligned}
& n_{0}=\frac{\theta}{\theta+(1-\theta)(1-\alpha) \rho^{D-1}} \frac{1-\rho}{2-\rho-\alpha}, \\
& n_{k}=\rho^{k-1}(1-\alpha) n_{0} \text { for } k=1, \ldots, D-1, \\
& n_{k}=0 \text { for } k \geq D .
\end{aligned}
$$

We denote by $n_{u}^{d}$ and $n_{p}^{d}$ the mass of unproductive and productive countries that have defaulted and are excluded from financial markets and by $n_{u, 1}^{d}$ the mass of countries that have just defaulted. We have the following expressions:

$$
\begin{aligned}
& n_{p}^{d}=\frac{(1-\theta)(1-\alpha) \rho^{D-1}}{\theta+(1-\theta)(1-\alpha) \rho^{D-1}} \frac{1-\rho}{2-\rho-\alpha}, \\
& n_{u}^{d}=\frac{(1-(1-\theta) \alpha) \rho^{D-1}}{\theta+(1-\theta)(1-\alpha) \rho^{D-1}} \frac{1-\alpha}{2-\rho-\alpha} .
\end{aligned}
$$

With our timing convention, the number of excluded countries re-entering financial markets after having being excluded is then $n_{-10}=\theta\left(\alpha n_{p}^{d}+(1-\rho) n_{u}^{d}\right)$ in each period. It is then straightforward to deduce that the overall population (excluded and participating countries) of productive countries amounts to $\frac{1-\rho}{2-\alpha-\rho}$ and that of unproductive countries to $\frac{1-\alpha}{2-\alpha-\rho}$. Note that these populations are independent of the default horizon $D$.

\section{B Proof of Proposition 1}

We prove Proposition 1 using several lemmas. Item 1 is proved in Lemma 2; Item 2 in Corollary 1; Item 3 in Lemma 4. Other lemmas are intermediary results. Item 4 is proven in Section B.2.

\section{B.1 Proof of Items 1 to 3}

Our first lemma is about the marginal utility of unproductive countries. 
Lemma 1 In any unproductive state, the country's marginal utility is greater than $1: u^{\prime}\left(c_{k}\right)>1$ for all $k$.

Proof. We consider a country in the unproductive state for $k \geq 1$ consecutive periods. Three, and only three, cases have to be distinguished.

1. No participation constraint is binding for the country, and none was binding in previous unemployment states $k^{\prime}<k$. So Euler equations (16) and (17) hold with equality and imply by induction with $q>\beta$ that $u^{\prime}\left(c_{k}\right)>1$.

2. A participation constraint is binding at $k$. This implies that we have $B_{k-1}<0$ (in case of a positive wealth, no participation constraint could be binding). We use the budget constraint $c_{k}=\bar{l}+B_{k-1}-q B_{k}$ to show that $c_{k} \leq \bar{l}$. First, if $B_{k} \geq 0$, we have $c_{k} \leq \bar{l}+B_{k-1} \leq \bar{l}$ since $B_{k-1}<0$. Second, if $B_{k}<0$, we have $c_{k}<\bar{l}+(1-q) B_{k} \leq \bar{l}$ since $q<1$ and $B_{k-1}<B_{k}$. We thus deduce that $c_{k} \leq \bar{l}$ and $u^{\prime}\left(c_{k}\right) \geq u^{\prime}(\bar{l})>1$.

3. No participation constraint is binding, but some was after $k^{\prime}<k$ consecutive unemployment period. We assume with loss of generality that $k^{\prime}$ was the last period before $k$ in which a participation constraint is binding. So Euler equations (17) hold with equality between $k^{\prime}$ and $k$. Since $u^{\prime}\left(c_{k^{\prime}}\right)>1$ (using the second point above), we deduce using Euler equations that $u^{\prime}\left(c_{k}\right)>1$ (as in the first point).

This concludes the proof.

The second lemma shows that the asset holding must be decreasing between two consecutive unemployment periods and proves Item 1.

Lemma 2 The asset holding path in unproductive states $\left(B_{k}\right)_{k \geq 1}$ is non-increasing with $k$.

Proof. The proof is done by contradiction. We consider a country in the unproductive state for $k \geq 1$ consecutive periods, such that $B_{k-1}<B_{k}$. Since $B_{k}>B_{k-1}$, the country cannot be constrained between $k$ and $k+1$ (periods in unemployment status), and the Euler equation (17) holds with equality for $k$. Since $q>\beta$, this Euler equation implies $\rho\left(u^{\prime}\left(c_{k+1}\right)-1\right)>u^{\prime}\left(c_{k}\right)-1>0$, where the last inequality is justified by Lemma 1 . With $\rho \in(0,1)$, we obtain $u^{\prime}\left(c_{k+1}\right)>u^{\prime}\left(c_{k}\right)$. 
Furthermore, the budget constraints (13) for $c_{k}$ and $c_{k+1}$ imply $B_{k}-B_{k-1}=c_{k+1}-c_{k}+$ $q\left(B_{k+1}-B_{k}\right)$, or using $c_{k+1}<c_{k}$ :

$$
B_{k+1}-B_{k} \geq q^{-1}\left(B_{k}-B_{k-1}\right)>0 .
$$

In consequence, no participation constraint can be binding after $k+2$ unproductive periods. We can then prove by induction that no participation constraint can bind after more than $k+1$ unproductive periods, as well as prove that $\left(c_{k^{\prime}}\right)_{k^{\prime} \geq k}$ is decreasing, while $\left(B_{k^{\prime}}\right)_{k^{\prime} \geq k}$ is increasing. Using budget constraints (13) repeatedly, we obtain then for any $k^{\prime} \geq k$, that $B_{k^{\prime}}-B_{k^{\prime}-1} \geq q^{-\left(k^{\prime}-k\right)}\left(B_{k}-B_{k-1}\right) \rightarrow_{k^{\prime} \rightarrow \infty} \infty$, which violates the transversality condition and cannot be an equilibrium. This concludes the proof.

The following lemma shows that a binding participation constraint in the productive state implies default in the unproductive one.

Lemma 3 If the participation constraint binds in the productive state for a given asset level $B$, then the country will default in the unproductive state for the same asset level B.

Proof. Assume that the constraint is binding for the first time in state $p$ at date $k+1$, for a negative asset level $B_{t}<0: V_{0}+B_{k}=V_{p}^{a}$. When unproductive, the utility was defined by:

$$
V_{k-1}=u\left(c_{D}\right)-\bar{l}+\beta(1-\rho) V_{p}^{a}+\beta \rho V_{k}
$$

Lemma 2 implies that we must have $B_{t}=B_{t+1}$ if no default. The utility $V_{k}$ is then defined as:

$$
V_{k}=u\left(\bar{l}+(1-q) B_{k}\right)-\bar{l}+\beta(1-\rho) V_{p}^{a}+\beta \rho V_{k},
$$

such that $V_{k}-V_{u}^{a}=u\left(\bar{l}+(1-q) B_{k}\right)-u(\bar{l})-\beta(1-\rho) \theta\left(V_{0}-V_{p}^{a}\right)<0$, since $B_{k}<0, q<1$ and $V_{0} \geq V_{p}^{a}$. This contradicts the absence of default in state $u$.

The following corollary is a direct consequence of Lemma 3 and proves Item 2.

Corollary 1 We have $\bar{B}^{u}>\bar{B}^{p}$.

The following result in our last lemma shows that an asset choice in $\left(\bar{B}^{p}, \bar{B}^{u}\right)$ is never optimal and proves Item 3. This concludes the proof of Proposition 1. 
Lemma 4 (Asset choice before default) Consider a country choosing $B_{D-1}<\bar{B}^{u}$ after $D-1$ consecutive unproductive periods, such that the country defaults in period $D$ if it remains unproductive for one extra period. Then, we must have $B_{D-1}=\bar{B}^{p}$ and $V_{p}^{c}\left(B_{D-1}\right)=V_{p}^{a}$.

The previous lemma states that the only optimal asset demand below $\bar{B}^{u}$ is $\bar{B}^{p}$. Therefore, in the period preceding default (that happens for sure in the next unproductive state if $B_{D-1}<$ $\bar{B}^{u}$ ), countries borrow as much as they can, conditional on repaying their debt when they become productive the next period. As a consequence, it is the period- $D$ participation constraint of productive countries which determine the maximal borrowing. If countries were not repaying when becoming productive in period $D$, they would default in all states of the world and the price of their debt at period $D-1$ would be 0 , which cannot be an equilibrium.

Proof. We proceed by contradiction. Assume that $V_{p}^{c}\left(B_{D-1}\right)>V_{p}^{a}$ in period $D-1$. As the country is defaulting at period $D$, the participating constraint of the unproductive country at period $D$ is violated. The first-order condition for the asset choice at period $D-1$ is (from equation $(7)),(1-\rho) q u^{\prime}\left(c_{D-1}\right)=\beta(1-\rho)$, or:

$$
q u^{\prime}\left(c_{D-1}\right)=\beta
$$

In words, the marginal disutility of debt is $(1-\rho) q u^{\prime}\left(c_{D-1}\right)$ and the country repays with probability $1-\rho$ in a state of the world where the marginal utility is 1 . Plugging this expression in (17) at $k=D-2$, we deduce $u^{\prime}\left(c_{D-2}\right)=\frac{\beta}{q}\left(1-\rho+\rho \frac{\beta}{q}\right)$, which implies $u^{\prime}\left(c_{D-2}\right)<1$, as

$\frac{\beta}{q}<1$. This contradicts Lemma 1. As a consequence, $V_{p}^{c}\left(B_{D-1}\right) \leq V_{p}^{a}$, and $V_{p}^{c}\left(B_{D-1}\right)=V_{p}^{a}$ (since $V_{p}^{c}\left(B_{D-1}\right)<V_{p}^{a}$ cannot be an optimal choice), which completes the proof.

\section{B.2 Proof of Item 4}

We start with a technical lemma providing the expression of $V_{0}^{d}$ in the equilibrium with default.

Lemma 5 When default occurs after $D \geq 2$ consecutive unproductive periods, the utility $V_{0}^{d}$ in 
the productive state can be expressed as follows:

$$
\begin{array}{r}
\left(1-\left(\beta \alpha+\beta^{2}(1-\rho)(1-\alpha) \sum_{j=1}^{D-1}(\beta \rho)^{j-1}\right)(1-\theta)\right) \frac{V_{0}^{d}-V_{p}^{a}}{\beta(1-\alpha)}=\sum_{j=1}^{D-1}(\beta \rho)^{j-1} v\left(c_{j}\right) \\
-(\beta \rho)^{D-2}(1-\rho)\left(q u^{\prime}\left(c_{D-1}\right)-\beta\right) B_{D-1}^{d},
\end{array}
$$

where $v(c)=u(c)-u(\bar{l})-u^{\prime}(c)(c-\bar{l})$ and $B_{D-1}^{d}$ solves: $V_{0}^{d}-V_{p}^{p}+B_{D-1}^{d}=0$.

\section{Proof.}

Using the expressions of autarky utilities (4) and (5), and of intertemporal utilities (31) and (32), we deduce that:

$$
\begin{aligned}
(1-\beta \alpha(1-\theta))\left(V_{0}^{d}-V_{p}^{a}\right) & =(\beta \alpha-q) B_{0}+\beta(1-\alpha)\left(V_{1}^{d}-V_{u}^{a}\right) \\
V_{k}^{d}-V_{u}^{a} & =u\left(c_{k}\right)-u(\bar{l})+\beta(1-\rho) B_{k}^{d}+\beta \rho\left(V_{k+1}^{d}-V_{u}^{a}\right) \\
& +\beta(1-\rho)(1-\theta)\left(V_{0}^{d}-V_{p}^{a}\right) .
\end{aligned}
$$

Substituting for $V_{1}^{d}-V_{u}^{a}$ and $B_{0}^{d}$ (using the budget constraint (13)), we get:

$$
\begin{aligned}
\left(1-\left(\beta \alpha+\beta^{2}(1-\rho)(1-\alpha)\right)(1-\theta)\right) \frac{V_{0}^{d}-V_{p}^{a}}{\beta(1-\alpha)} & =\frac{\beta \alpha-q}{\beta(1-\alpha)}\left(c_{1}-\bar{l}+q B_{1}^{d}\right) \\
& +u\left(c_{1}\right)-u(\bar{l})+\beta(1-\rho) B_{1}^{d}+\beta \rho\left(V_{2}^{d}-V_{u}^{a}\right),
\end{aligned}
$$

or using the Euler equation (28) and the definition $v(c)=u(c)-u(\bar{l})-u^{\prime}(c)(c-\bar{l})$, we obtain:

$$
\left(1-\left(\beta \alpha+\beta^{2}(1-\rho)(1-\alpha)\right)(1-\theta)\right) \frac{V_{0}-V_{p}^{a}}{\beta(1-\alpha)}=v\left(c_{1}\right)+\left(\beta(1-\rho)-u^{\prime}\left(c_{1}\right) q\right) B_{1}+\beta \rho\left(V_{2}-V_{u}^{a}\right)
$$

Proceeding similarly, we can prove by induction that for any $k<D-1$, we have:

$$
\begin{aligned}
\left(1-\left(\beta \alpha+\beta^{2}(1-\rho)(1-\alpha) \sum_{j=1}^{k}(\beta \rho)^{j-1}\right)(1-\theta)\right) & \frac{V_{0}^{d}-V_{p}^{a}}{\beta(1-\alpha)}=\sum_{j=1}^{k}(\beta \rho)^{j-1} v\left(c_{j}\right) \\
& +(\beta \rho)^{k}\left(V_{k+1}^{d}-V_{u}^{a}-u^{\prime}\left(c_{k+1}\right) B_{k}^{d}\right) .
\end{aligned}
$$

Plugging into the previous expression for $k=D-2$, the expression $V_{D-1}^{d}-V_{u}^{a}=u\left(c_{D-1}\right)-$ $u(\bar{l})-\beta(1-\rho) \theta\left(V_{0}^{d}-V_{p}^{a}\right)$ and the budget constraint for $B_{D-1}^{d}$, we finally deduce equality (52), which concludes the proof. 
We now consider an equilibrium where no participation constraint ever binds. This equilibrium corresponds to the case where the natural borrowing limit binds before participation constraints. We prove here the following lemma (which is more general than Item 4).

Lemma 6 An equilibrium with never-binding credit-constraint will not exist if one of the following conditions holds:

1. $u^{\prime}(0)>\infty$;

2. $u(0)=-\infty$;

3. $\bar{l}$ not too small - sufficient condition can be found in equation (56).

Proof. In an equilibrium with never-binding credit constraints, the consumption path $\left(c_{k}\right)_{k \geq 1}$ is determined by Euler equations (16) and (17), where the latter holds for all $k \geq 1$. This implies increasing marginal utilities that asymptotically converge to infinity: $u^{\prime}\left(c_{k}\right) \nearrow \infty$.

First, if Point 1 does not hold, the consumption path is not well-defined for all $k$ - because of $u^{\prime}\left(c_{k}\right) \nearrow \infty$ and equilibrium does not exist. Now, Point 1 holds, we have $c_{k} \searrow 0$. The asset demand path $\left(B_{k}\right)_{k \geq 0}$ is then deduced from budget constraints (13), which implies: $B_{k} \rightarrow_{k}-\frac{\bar{l}}{1-q}$. The utility path $\left(V_{k}^{n b}\right)_{k \geq 0}$ (np standing for never-binding participation constraint) is determined by a recursion similar to $(21)$ and $(22)$, where the latter holds for all $k \geq 1$. We deduce that $V_{k}^{n b} \rightarrow_{k} V_{\infty}^{n b}$, which verifies:

$$
(1-\beta \rho)\left(V_{\infty}^{n b}-V_{u}^{a}\right)=u(0)-u(\bar{l})-\beta(1-\rho) \frac{\bar{l}}{1-q}+\beta(1-\rho)(1-\theta)\left(V_{0}^{n b}-V_{p}^{a}\right) .
$$

If Point 2 does not hold, we have $u(0)=-\infty$ and $V_{\infty}^{n b}<V_{u}^{a}$. The equilibrium does not exist. We now assume that Point 2 holds.

We now consider Point 3. We deduce from Lemma 5 (that can easily be extended to $V_{0}^{n b}$ ):

$$
\left(1-\left(\beta \alpha+\frac{\beta^{2}(1-\rho)(1-\alpha)}{1-\beta \rho}\right)(1-\theta)\right) \frac{V_{0}^{n b}-V_{p}^{a}}{\beta(1-\alpha)} \leq \frac{u\left(c_{0}\right)-u(\bar{l})-\left(c_{0}-\bar{l}\right)}{1-\beta \rho}
$$


and that with (55):

$$
\begin{aligned}
(1-\beta \rho)\left(V_{\infty}-V_{u}^{a}\right) & \leq u(0)-u(\bar{l})-\beta(1-\rho) \frac{\bar{l}}{1-q} \\
& +\frac{(1-\beta \rho) \beta^{2}(1-\alpha)(1-\rho)}{(1-\beta)(1+\beta-\beta \alpha-\beta \rho)}\left(u\left(c_{0}\right)-u(\bar{l})-\left(c_{0}-\bar{l}\right)\right),
\end{aligned}
$$

which can be shown to be negative whenever $\bar{l}$ is not too small. So, if Item 3, equilibrium does not exist. A sufficient condition on $\bar{l}$ for the equilibrium not to exist is:

$$
\begin{aligned}
& u(0)-u(\bar{l})-\beta(1-\rho) \frac{\bar{l}}{1-q} \\
& +\frac{(1-\beta \rho) \beta^{2}(1-\alpha)(1-\rho)}{(1-\beta)(1+\beta-\beta \alpha-\beta \rho)}\left(u\left(c_{0}\right)-u(\bar{l})-\left(c_{0}-\bar{l}\right)\right)<0 .
\end{aligned}
$$

Lemma 6 proves Item 4 of Proposition 1, for CRRA utility function with $\sigma \geq 1$ (Assumption 1 holds).

\section{Computation of the equilibria}

\section{C.1 Default equilibrium}

We can provide an upper value for the equilibrium number of periods before default $D$ (for a given $q$ ). This upper bound is useful to compute the equilibrium.

Lemma 7 (Finite D) Define,

$$
D_{\max } \equiv \min \left\{k \geq 1: u^{\prime}\left(c_{k}\right)>u^{\prime}(\bar{l})\right\}
$$

where the path of marginal utilities $\left(u^{\prime}\left(c_{k}\right)\right)_{k \geq 0}$ is computed using Euler equations (16)-(17).

We have: $D_{\max }<+\infty$ and necessarily $D \leq D_{\max }$.

Proof. The proof is straightforward. First, marginal consumption utilities $\left(u^{\prime}\left(c_{k}\right)\right)_{k \geq 0}$ are strictly increasing with $k$, whenever $q>\beta$, which guarantees that $D_{\max }<\infty$. Second, let us assume that $D=D_{\max }+1$, such that the utility in the period before default verifies: $V_{D-1}^{d,(D)}=$ $u\left(c_{D_{\max }}\right)-\bar{l}+\beta(1-\rho) V_{p}^{a}+\beta \rho V_{u}^{a}$. Since $u\left(c_{D_{\max }}\right)<u(\bar{l})$, it implies that $V_{D-1}<V_{u}^{a}$ and the 
default equilibrium for $D_{\max }+1$ does not exist.

We now explain how to compute a default equilibrium for a given asset price $q$. The consumption path $\left(c_{k}\right)_{k \geq 0}$ can then be computed using Euler equations $(16)-(17)$, until $u^{\prime}\left(c_{k}\right)>u^{\prime}(\bar{l})$. This enables us to start with $D=D_{\max }$, as suggested in Lemma 7 . Using the consumption path truncated for $k \leq D$, we compute $V_{0}^{d}$ using a fixed-point iteration (the superscript in $(D)$ is dropped here in the absence of ambiguity). Indeed, for a given value of $V_{0}^{d}$, we can compute $B_{D-1}^{d}$ using the default constraint $(23)$. The utility path $\left(V_{k}^{d}\right)_{k}$ and the asset choice path $\left(B_{k}^{d}\right)$ can then be deduced using budget constraints (13)-(14) and utility recursions (21)-(20). In particular, this sequence of operations generates a mapping from an initial $V_{0}^{d}$ to an updated $V_{0}^{d}$, such that the equilibrium is computed when $V_{0}^{d}$ is a fixed point of this mapping. A side effect of this fixed point computation is the computation of the equilibrium utility path $\left(V_{k}^{d}\right)_{k}$, which enables checking whether condition (25) holds. Finally, it remains to compute the optimal $D$, such that condition (26) holds. Condition (27) can finally be verified once the no-default equilibrium allocations have been computed - see Section C.2.

\section{C.2 No-default equilibrium}

The no-default equilibrium can be computed in a very similar manner as the default equilibrium, with a few differences. As for the default-equilibrium, we can state a lemma similar to Lemma 7 regarding the fact that the participation constraint is binding for a finite $T$.

Lemma 8 (Finite $T$ ) The no-default equilibrium only exists for $2 \leq T \leq T_{\max }$, where $2 \leq$ $D_{\max } \leq T_{\max }<\infty$.

Proof. We consider a no-default equilibrium where the participation constraint binds after $T$ consecutive unproductive periods. The asset demand $B_{T}^{n}$ is defined from equation (33), while the utility $V_{T-1}^{n}$ is characterized by (32) for $k=T-1$. The difference of the two yields:

$$
V_{T-1}^{n}-V_{u}^{a}=u\left(c_{T-1}\right)-u\left(\bar{l}+(1-q) B_{T}^{n}\right),
$$


where $c_{T-1} \rightarrow_{T \rightarrow \infty} 0$, while $\bar{l}+(1-q) B_{T}^{n}$ remains bounded away from 0 for large $T$. Indeed, using (33) and the definition of $V_{p}^{a}$, we deduce that $B_{T}^{n}$ is characterized by:

$$
0=u\left(\bar{l}+(1-q) B_{T}^{n}\right)-u(\bar{l})+\beta(1-\rho)(1-\theta)\left(V_{0}^{n}-V_{p}^{a}\right)+\beta(1-\rho) B_{T}^{n},
$$

which cannot hold if $\bar{l}+(1-q) B_{T}^{n} \rightarrow_{T \rightarrow \infty} 0$ because of the arguments presented in Section B.2 (see equation (55), which is shown to be always negative). We deduce then from (58) that when $T$ is sufficiently large, we have $V_{T-1}^{n}-V_{u}^{a}<0$ and the no-default equilibrium cannot exist. There exists thus $T_{\max }$, such that for $T \geq T_{\max }$, the no-default equilibrium does not exist.

As a final remark, note that $T_{\max }$ can be defined as:

$$
T_{\max }=\arg \min \left\{T \geq 0: u\left(c_{T-1}\right)<u\left(\bar{l}+(1-q) B_{T}^{n}\right)\right\} .
$$

The drawback of this definition is that $B_{T}^{n}$ is an endogenous quantity, which requires the full resolution of the model, because of the dependence in $V_{0}^{n}$.

A first difference with the default equilibrium is the absence of a simple explicit closed-form expression for $T_{\max }$, so we need to start from some acceptable value for $T$ ( $\operatorname{such}$ as $T=2$ ). The consumption path $\left(c_{k}\right)_{1 \leq k \leq T}$ can then be computed using equations (28)-(29). We can then compute $V_{0}^{n}$ as the fixed point of a mapping, which however slightly differs from the one for the default equilibrium. Indeed, an initial value $V_{0}^{n}$ yields $B_{T}^{n}$ using equation (33) - and not the default constraint (23). We can deduce an updated value of $V_{0}^{n}$ using budget constraints (13) and utility recursion (31)-(32). The equilibrium value $V_{0}^{n}$ is obtained as a fixed point of this mapping. As in the default equilibrium, we obtain equilibrium utility path $\left(V_{k}^{n}\right)_{k}$ as a side computation of the fixed-point mapping, and we can then check that equilibrium conditions hold - which are (35)-(36) in the no-default case. Finally, we find the optimal $T$ until condition (37) holds - as done in the default case for $D$.

Using the computations of Section C.1, we can compare $V_{0}^{d}$ and $V_{0}^{n}$ to determine which of the default or no-default equilibria exist - for which conditions (27) and (38) hold. Note that it is possible for some parameter values that the only acceptable equilibrium is an autarky equilibrium. 


\section{Proof of Proposition 4}

\section{D.1 Structure of the constrained-efficient equilibrium with default}

We use the same notation as in the market economy of Section 2, except that we add a tilde for the quasi-planner allocation. To simplify the exposition, we directly assume that productive countries consume the same amount, which is a direct outcome of the labor choice made in those countries by the quasi-planner. First, the planner chooses the optimal default decision $\tilde{D}$. The quasi-planner then chooses the consumption $\tilde{c}_{0}$, net savings $\tilde{B}_{0}^{d}$, and labor supply $\tilde{l}_{k 0}^{d}$ of productive countries that have been unproductive for $k=-1,0, \ldots, \tilde{D}$ consecutive periods. The planner also chooses the consumption $\tilde{c}_{k}$ and the savings $\tilde{B}_{k}^{d}$ of unproductive countries for $k=1,2, \ldots, \tilde{D}$ consecutive periods. As before, the net wealth of countries reentering the financial markets is zero, $\tilde{B}_{-1}^{d}=0$. The quasi-planner is concerned with the instantaneous aggregate utility $\tilde{U}$ expressed as:

$$
\tilde{U}=\sum_{k=-1}^{\tilde{D}-1} \tilde{n}_{k 0}\left(u\left(\tilde{c}_{0}\right)-\tilde{l}_{k 0}\right)+\sum_{k=1}^{\tilde{D}-1} \tilde{n}_{k}\left(u\left(\tilde{c}_{k}\right)-\bar{l}\right)+\tilde{n}_{p}^{d}\left(u\left(c_{0}\right)-c_{0}\right)+\tilde{n}_{u}^{d}(u(\bar{l})-\bar{l}),
$$

where the tilde in population shares highlights their dependence in $\tilde{D}$. Formal expressions of population shares have the same expression as in the market economy, given in Appendix A. The quasi-planner's program can be expressed recursively as follows:

$$
\tilde{W}=\max _{\left\{\tilde{l}_{k 0}^{d}\right\}_{-1 \leq k<\tilde{D}-1},\left\{\tilde{c}_{k}\right\}_{1 \leq k<\tilde{D}-1},\left\{\tilde{B}_{k}^{d}\right\}_{0 \leq k<\tilde{D}-1}} \tilde{U}+\beta \tilde{W}^{\prime},
$$

subject to the set of country budget constraints, which are similar to (13)-(15):

$$
\begin{aligned}
\tilde{B}_{k-1}^{d} & =\tilde{c}_{k}-\bar{l}+\tilde{q} \tilde{B}_{k}, \quad 1 \leq k<\tilde{D}-1, \\
\tilde{B}_{\tilde{D}-2}^{d} & =\tilde{c}_{D-1}-\bar{l}+\tilde{q}(1-\rho) \tilde{B}_{\tilde{D}-1}^{d}, \\
\tilde{c}_{0}+\tilde{q} \tilde{B}_{0}^{d} & =\tilde{l}_{k 0}^{d}+\tilde{B}_{k}^{d}, \quad-1 \leq k \leq \tilde{D}-1,
\end{aligned}
$$


and subject to individual participation constraints (similar to (25) in the market economy):

$$
\begin{gathered}
\tilde{V}_{k 0}^{d} \geq \tilde{V}_{p}^{a}, \quad-1 \leq k<D, \\
\tilde{V}_{k}^{d} \geq \tilde{V}_{u}^{a}, \quad 1 \leq k<D .
\end{gathered}
$$

The quantities $\tilde{V}_{k 0}^{d}$ and $\tilde{V}_{k}^{d}$ represent the intertemporal welfare of different country types. The last constraint of the quasi-planner program is the financial market clearing:

$$
\sum_{k=0}^{\tilde{D}-2} \tilde{n}_{k} \tilde{B}_{k}^{d}+(1-\rho) \tilde{n}_{\tilde{D}-1} \tilde{B}_{\tilde{D}-1}^{d}=0 .
$$

The key difference between the market economy and the constrained-efficient allocation is that the quasi-planner internalizes the effect of saving and default decisions on the price of the safe asset, and thus on aggregate risk-sharing.

The solution of the quasi-planner program is straightforward. We now present the corresponding first-order conditions in order to provide insights into the constrained-efficient allocation. We denote by $\lambda$ the Lagrange multiplier of the financial market clearing constraint (68), which corresponds to the social value for the planner of one additional unit of the world safe asset. Euler equations can be written as:

$$
\begin{aligned}
\tilde{q}+\lambda & =\beta\left(\alpha+(1-\alpha) u^{\prime}\left(\tilde{c}_{1}\right)\right), \\
\tilde{q} u^{\prime}\left(\tilde{c}_{k}\right)+\lambda & =\beta\left(1-\rho+\rho u^{\prime}\left(\tilde{c}_{k+1}\right)\right), \quad 1 \leq k \leq \tilde{D}-2, \\
q \tilde{u}^{\prime}\left(c_{\tilde{D}-1}\right)+\lambda & \geq \beta .
\end{aligned}
$$

The price is determined by the first-order condition:

$$
\sum_{k=0}^{D-2} n_{k} B_{k} u^{\prime}\left(c_{k}\right)+(1-\rho) n_{D-1}^{u} B_{D-1} u^{\prime}\left(c_{D-1}\right)=0 .
$$

Before commenting on these expressions, it is worth noting that when $\lambda=0$, i.e., when there is no internalization of the effect of saving on prices, we find the same first-order conditions as in the market economy. The difference between the two allocations therefore stems solely from the internalization of the pecuniary externality.

The internalization of the pecuniary externality affects the Euler equations through the addi- 
tional net gain of saving, which is captured by $\lambda$. Furthermore, the quasi-planner's price setting implies an additional first-order condition, which is equation (72). This equation stipulates that the quasi-planner sets the price of the safe asset such that the redistributive effects maximize welfare across buyers and sellers.

\section{D.2 Proof of Proposition 4}

We now show that the quasi-planner allocation is either autarky or it is characterized by $\tilde{q}+\lambda=\beta$ and $u^{\prime}\left(\tilde{c}_{k}\right)=1$ for $k=0, \ldots, \tilde{D}-1$. We proceed in three steps.

Step 1. If $\tilde{q}+\lambda=\beta$, equations (69)-(71) imply $u^{\prime}\left(\tilde{c}_{1}\right)=1$, and then $u^{\prime}\left(\tilde{c}_{k}\right)=1$ for $k=$ $1, \ldots, \tilde{D}-1$. Condition (72) holds (as in any equilibrium).

Step 2. We show that there is no constrained-efficient equilibrium where $\tilde{q}+\lambda>\beta$. We proceed by contradiction. Assume that $\tilde{q}+\lambda>\beta$. First, from equation (69), we obtain $u^{\prime}\left(\tilde{c}_{k}\right)>1$. Then using (70), we recursively show that $u^{\prime}\left(\tilde{c}_{k+1}\right)>u^{\prime}\left(\tilde{c}_{k}\right)$, for $k=0, \ldots, \tilde{D}-1$ and $\left(\tilde{c}_{k}\right)_{k}$ is decreasing. Second, we already know that $\left(B_{k}^{d}\right)_{k}$ is decreasing.

We now show that the financial market clearing condition (68) and the first-order condition (72) cannot hold at the same time. Let us define $k_{0}$ as the index such that $B_{k_{0}}^{d} \geq 0>B_{k_{0}+1}^{d}$. The index $k_{0}$ exists because $\left(B_{k}^{d}\right)_{k}$ is decreasing and equality (68) holds. This implies $\tilde{B}_{k}^{d} \geq 0$ for all $k=0, \ldots, k_{0}$ and $\tilde{B}_{k}^{d}<0$ for $k=k_{0}+1, \ldots, \widetilde{D}-2$. Since $\left(\tilde{c}_{k}\right)_{k}$ is decreasing, we deduce:

$$
\sum_{k=0}^{k_{0}} \tilde{n}_{k} \tilde{B}_{k}^{d} u^{\prime}\left(\tilde{c}_{k}\right)<u^{\prime}\left(\tilde{c}_{k_{0}}\right) \sum_{k=0}^{k_{0}} \tilde{n}_{k} \tilde{B}_{k}^{d}
$$

as well as:

$$
\begin{gathered}
-\left(\sum_{k=k_{0}+1}^{\tilde{D}-2} \tilde{n}_{k} \tilde{B}_{k}^{d} u^{\prime}\left(\tilde{c}_{k}\right)+(1-\rho) \tilde{n}_{\tilde{D}-1} \tilde{B}_{\tilde{D}-1}^{d} u^{\prime}\left(\tilde{c}_{D-1}\right)\right)> \\
-u^{\prime}\left(\tilde{c}_{k_{0}+1}\right)\left(\sum_{k=k_{0}+1}^{\tilde{D}-2} \tilde{n}_{k} \tilde{B}_{k}^{d}+(1-\rho) \tilde{n}_{\tilde{D}-1} \tilde{B}_{\tilde{D}-1}^{d}\right) .
\end{gathered}
$$


Furthermore, the financial market clearing condition (68) implies:

$$
\sum_{k=0}^{k_{0}} \tilde{n}_{k} \tilde{B}_{k}^{d}=-\left(\sum_{k=k_{0}+1}^{\tilde{D}-2} \tilde{n}_{k} \tilde{B}_{k}^{d}+(1-\rho) \tilde{n}_{\tilde{D}-1} \tilde{B}_{\tilde{D}-1}^{d}\right)
$$

which with equations (73) and (74) implies:

$$
-\left(\sum_{k=k_{0}+1}^{\tilde{D}-2} \tilde{n}_{k} \tilde{B}_{k}^{d} u^{\prime}\left(\tilde{c}_{k}\right)+(1-\rho) \tilde{n}_{\tilde{D}-1} \tilde{B}_{\tilde{D}-1}^{d} u^{\prime}\left(\tilde{c}_{D-1}\right)\right)>\sum_{k=0}^{k_{0}} \tilde{n}_{k} \tilde{B}_{k}^{d} u^{\prime}\left(\tilde{c}_{k}\right) .
$$

The last inequality shows that the condition (72) cannot hold, which is a contradiction.

Step 3. We consider the case $\tilde{q}+\lambda<\beta$ and show that no constrained-efficient equilibrium exists. The proof is analogous to the one in the second step, except that $\left(\tilde{c}_{k}\right)_{k}$ and $\left(\tilde{B}_{k}^{d}\right)_{k}$ are shown to be increasing (instead of decreasing). We still obtain a contradiction by showing that the financial clearing (68) and the first-order condition (72) cannot simultaneously hold.

\section{E Constrained efficiency in the equilibrium without default}

We now assume that countries do not default in the constrained-efficient equilibrium. We use the same notation as in the market economy of Section 3, except that we add a tilde for the quasiplanner allocation. The quasi-planner can choose how much each country can save, consume, and work, internalizing the financial market clearing condition. The constrained-efficient allocation of the quasi-planner is summarized in the next proposition.

Proposition 6 (Constrained-efficient allocation in the absence of default) The constrained-efficient allocation in a no-default equilibrium is characterized by a credit-constraint horizon $\tilde{T}$ and allocations $\tilde{c}_{k}^{n}=u^{\prime-1}(1)$ for $k=0, \ldots, \tilde{T}$.

As in Proposition 4, the constrained-efficient equilibrium features full risk-sharing among a subgroup of countries. Countries which are not in this group do not default, but are at the endogenous credit constraint $\bar{B}^{u}$.

Overall, the quasi-planer implements the constrained-efficient allocation that features default or no-default, by choosing the one associated with the highest aggregate welfare. Since the 
structure of each of the two types of constrained-efficient equilibria is explicit, the aggregate welfare in each of the two situations can easily be computed.

\section{E.1 Structure of the constrained-efficient equilibrium without default}

The planner chooses the optimal default decision $\tilde{T}$, as well as the consumption $\tilde{c}_{0}$, net savings $\tilde{B}_{0}^{n}$, and labor supply $\tilde{l}_{k 0}^{n}$ of productive countries that have been unproductive for $k=$ $-1,0, \ldots, \tilde{T}$ consecutive periods. The planner also chooses the consumption $\tilde{c}_{k}$ and the savings

$\tilde{B}_{k}^{n}$ of unproductive countries for $k=1,2, \ldots, \tilde{T}$ consecutive periods. The planner is concerned with the instantaneous aggregate utility $\tilde{U}$ expressed as:

$$
\tilde{U}=\sum_{k=-1}^{\tilde{T}} \tilde{n}_{k 0}\left(u\left(\tilde{c}_{0}\right)-\tilde{l}_{k 0}\right)+\sum_{k=1}^{\tilde{T}} \tilde{n}_{k}\left(u\left(\tilde{c}_{k}\right)-\bar{l}\right)+\tilde{n}^{T}\left(u\left(\tilde{c}_{T+1}\right)-\tilde{l}_{T+1}\right),
$$

where $\tilde{n}^{T}$ is the fraction of countries that are unproductive for more than $T$ periods (and which are thus at the credit constraint). The planner's program can be expressed recursively as:

$$
\tilde{W}=\max _{\left\{\tilde{l}_{k 0}^{n}\right\}_{-1 \leq k<\tilde{D}-1},\left\{\tilde{c}_{k}\right\}_{1 \leq k<\tilde{D}-1},\left\{\tilde{B}_{k}^{n}\right\}_{0 \leq k<\tilde{D}-1}} \tilde{U}+\beta \tilde{W}^{\prime},
$$

subject to the set of country budget constraints, which are similar to (13)-(15):

$$
\begin{aligned}
\tilde{B}_{k-1}^{n} & =\tilde{c}_{k}-\bar{l}+\tilde{q} \tilde{B}_{k}^{n}, \quad k \geq 1 \\
\tilde{c}_{0}+\tilde{q} \tilde{B}_{0}^{n} & =\tilde{l}_{k 0}^{n}+\tilde{B}_{k}^{n}, \quad k \geq 1,
\end{aligned}
$$

and subject to individual participation constraints (similar to (35) and (36)):

$$
\begin{gathered}
\tilde{V}_{k 0}^{n} \geq \tilde{V}_{p}^{a}, \quad 0 \leq k, \\
\tilde{V}_{k}^{n} \geq \tilde{V}_{u}^{a}, \quad 1 \leq k .
\end{gathered}
$$

The last constraint of the quasi-planner program is the financial market clearing:

$$
\sum_{k=0}^{\tilde{T}} \tilde{n}_{k} \tilde{B}_{k}^{n}+\tilde{n}^{T} B_{T}^{n}=0
$$

As before, we denote by $\lambda$ the Lagrange multiplier of the financial market clearing constraint 
(81), which corresponds to the social value for the planner of one additional unit of the world safe asset. Euler equations can be written as:

$$
\begin{aligned}
\tilde{q}+\lambda & =\beta\left(\alpha+(1-\alpha) u^{\prime}\left(\tilde{c}_{1}\right)\right), \\
\tilde{q} u^{\prime}\left(\tilde{c}_{k}\right)+\lambda & =\beta\left(1-\rho+\rho u^{\prime}\left(\tilde{c}_{k+1}\right)\right), \quad 1 \leq k \leq \tilde{T}-1, \\
q \tilde{u}^{\prime}\left(c_{\tilde{T}}\right)+\lambda \geq \beta\left(1-\rho+\rho u^{\prime}\left(c_{T+1}\right)\right), & T \leq k .
\end{aligned}
$$

The price is determined by the first-order condition:

$$
\sum_{k=0}^{\infty} n_{k} B_{k}^{n} u^{\prime}\left(c_{k}\right)=0
$$

\section{E.2 Proof of Proposition 4}

We now show that the quasi-planner allocation is characterized by $\tilde{q}+\lambda=\beta$ and $u^{\prime}\left(\tilde{c}_{k}\right)=1$ for $k=0, \ldots, \tilde{T}$. We proceed in three steps.

Step 1. If $\tilde{q}+\lambda=\beta$, equations (82)-(84) imply $u^{\prime}\left(\tilde{c}_{1}\right)=1$, and then $u^{\prime}\left(\tilde{c}_{k}\right)=1$ for $k=1, \ldots, \tilde{T}$. Condition (85) holds (as in any equilibrium).

Step 2. We can show that there is no constrained-efficient equilibrium where $\tilde{q}+\lambda>\beta$, and the proof is the same as for the default case.

Step 3. We consider the case $\tilde{q}+\lambda<\beta$ and show that no constrained-efficient equilibrium exists. The proof is again analogous to the one in the second step, except that $\left(\tilde{c}_{k}\right)_{k}$ and $\left(\tilde{B}_{k}^{n}\right)_{k}$ are shown to be increasing (instead of decreasing). We still obtain a contradiction by showing that the financial clearing (81) and the first-order condition (85) cannot simultaneously hold.

\section{F Proof of Proposition 5}

\section{F.1 Full risk-sharing implementation}

We now provide the amount of liquidity implementing full risk-sharing and finite default horizon $D$. Existence conditions are then discussed. An equilibrium in the IFI economy is thus a default 
horizon $D$, an IFI policy $(F, \tau)$, an asset price $q$, allocations $\left\{l_{k}\right\}_{-1 \leq k<D},\left\{c_{k}, B_{k}\right\}_{0 \leq k<D}$, such that: 1) for a given $q$ and $(F, \tau)$, allocations are consistent with individual country programs; 2) the financial market clears and (41) holds; and 3) the IFI policy is balanced and (40) holds.

Then full risk-sharing is implemented in the IFI economy when $q=\beta$. Indeed, as $q=\beta$, the first-order conditions, identical to (16)-(51), for $k=0, \ldots, D-1$ yield $c_{0}=c_{k}=u^{\prime-1}(1) \equiv c$. Using the tractability in our framework, we exhibit the 3 equations determining the size of the IFI for any finite $D$.

First equation. The budget constraints of unproductive countries, now including the payment $\tau$, lead after backward iteration to:

$$
B_{k}=\frac{B_{0}}{\beta^{k}}+(c-\bar{l}+\tau) \frac{1-\beta^{-k}}{1-\beta},
$$

where $B_{0}$ is the saving of participating productive countries. The welfare of participating unproductive countries is:

$$
V_{k}=u(c)-\bar{l}+\beta(1-\rho) V_{p}^{c}(0)+\beta(1-\rho) B_{k}+\beta \rho V_{k+1},
$$

which yields after forward iteration:

$$
\begin{aligned}
V_{1} & =\left(u(c)-\bar{l}+\beta(1-\rho) V_{p}^{c}(0)\right) \frac{1-(\beta \rho)^{D-1}}{1-\beta \rho} \\
& +(c-\bar{l}+\tau) \frac{\beta(1-\rho)}{1-\beta} \frac{1-(\beta \rho)^{D-1}}{1-\beta \rho} \\
& +\left(B_{0}-\frac{c-\bar{l}+\tau}{1-\beta}\right)\left(1-\rho^{D-1}\right)+(\beta \rho)^{D-1} V_{u}^{a} .
\end{aligned}
$$

The welfare of a productive participating country with a wealth 0 in the IFI economy is:

$$
V_{p}^{c}(0)=u(c)-\left(c+\tau+\beta B_{0}\right)+\beta \alpha V_{p}^{c}(0)+\beta \alpha B_{0}+\beta(1-\alpha) V_{1},
$$


or using the expression (87) of $V_{1}$ :

$$
\begin{aligned}
(1-\beta \alpha) V_{p}^{c}(0) & =u(c)-\left(c+\tau+\beta B_{0}\right)+\beta \alpha B_{0} \\
& +\left(u(c)-\bar{l}+\beta(1-\rho) V_{p}^{c}(0)\right) \beta(1-\alpha) \frac{1-(\beta \rho)^{D-1}}{1-\beta \rho} \\
& +(c-\bar{l}+\tau) \frac{\beta^{2}(1-\alpha)(1-\rho)}{1-\beta} \frac{1-(\beta \rho)^{D-1}}{1-\beta \rho} \\
& +\beta(1-\alpha)\left(B_{0}-\frac{c-\bar{l}+\tau}{1-\beta}\right)\left(1-\rho^{D-1}\right)+(\beta \rho)^{D-1} \beta(1-\alpha) V_{u}^{a} .
\end{aligned}
$$

As $V_{p}^{c}\left(B_{D-1}\right)=V_{p}^{a}$, we have $V_{p}^{c}(0)=V_{p}^{a}-B_{D-1}$ or using $(86)$ :

$$
V_{p}^{c}(0)=V_{p}^{a}-\beta^{-(D-1)} B_{0}-\frac{1-\beta^{-(D-1)}}{1-\beta}(c-\bar{l}+\tau) .
$$

Substituting (89) into (88), we obtain:

$$
\Psi_{1} \tau=\Psi_{2}-\Psi_{3} B_{0}
$$

with:

$$
\begin{aligned}
\Psi_{1} & =\beta^{2}(1-\alpha)(1-\rho) \frac{1-(\beta \rho)^{D-1}}{1-\beta \rho} \frac{\beta^{-(D-1)}}{1-\beta} \\
& +\frac{1}{1-\beta}\left(\rho^{D-1} \beta(1-\alpha)-\beta^{-(D-1)}(1-\beta \alpha)\right) \\
\Psi_{2}= & -(u(c)-\bar{l})\left(1+\beta(1-\alpha) \frac{1-(\beta \rho)^{D-1}}{1-\beta \rho}\right) \\
& -(c-\bar{l})\left(\beta^{2}(1-\alpha)(1-\rho) \frac{1-(\beta \rho)^{D-1}}{1-\beta \rho} \frac{\beta^{-(D-1)}}{1-\beta}\right. \\
& \left.\quad+\frac{1}{1-\beta}\left(\rho^{D-1} \beta(1-\alpha)-\beta^{-(D-1)}(1-\beta \alpha)\right)\right) \\
& \left(1-\beta \alpha-\beta^{2}(1-\alpha)(1-\rho) \frac{1-(\beta \rho)^{D-1}}{1-\beta \rho}\right) V_{p}^{a}-(\beta \rho)^{D-1} \beta(1-\alpha) V_{u}^{a}, \\
\Psi_{3}= & \left(1-\beta \alpha-\beta(1-\alpha) \frac{\beta(1-\rho)+(1-\beta)(\beta \rho)^{D-1}}{1-\beta \rho}\right) \beta^{-(D-1)} .
\end{aligned}
$$

The two value functions $V_{p}^{a}$ and $V_{u}^{a}$ are endogenous values, as the probability to reenter is positive. The functions can be expressed as a function of $V_{p}^{c}(0)$, which is the value of a country reentering the market. Using (88), they can be written as a function of $B_{0}$ and $\tau$. 
Second equation. Using equations (86) and (47), the IFI clearing condition becomes:

$$
\begin{aligned}
& \frac{F}{(1-\alpha) n_{0}}=\frac{B_{0}}{1-\alpha}+\sum_{k=1}^{D-1} \rho^{k-1}\left(\frac{B_{0}}{\beta^{k}}+(c-\bar{l}+\tau) \frac{1-\beta^{-k}}{1-\beta}\right), \\
& \quad=B_{0}\left(\frac{1}{1-\alpha}+\frac{1-\rho^{D-1} \beta^{-(D-1)}}{\beta-\rho}\right)+\frac{c-\bar{l}+\tau}{1-\beta}\left(\frac{1-\rho^{D-1}}{1-\rho}-\frac{1-\rho^{D-1} \beta^{-(D-1)}}{\beta-\rho}\right) .
\end{aligned}
$$

Third equation. The third equation is the budget constraint of the IFI (40):

$$
(1-\beta) F=n_{p} \tau
$$

The three linear equations (90), (91), and (92) form a linear system in three unknowns in $B_{0}, F, \tau$. Except particular cases (which would correspond to a non-invertible matrix for the linear system - which is a zero-measure set), there is always a solution. These three equations ensure that there exists an IFI economy equilibrium with a finite $F^{*}$, and $q=\beta$.

Existence conditions. Note that if productive countries are saving $B_{0}$ when belonging to the IFI risk-sharing arrangement, then the optimal saving decision when unproductive is given by the sequence $B_{k}$ satisfying Euler conditions and provided above. Assumption 4 in Section 5.2 ensures that the IFI can impose a maximum amount of saving $B_{0}$ (whereas productive countries would like to save more). First, the equilibrium construction ensures that the utility of participating countries is higher than the one if they default, which determines the optimal default horizon $D$. Second, the equilibrium construction ensures that the inter-temporal welfare of productive participating countries is higher than the one in default, as $V_{p}^{c}\left(B_{D-1}\right)=V_{p}^{a}$.

The last participating condition must ensure that countries accept to join the IFI risk-sharing arrangement. As productive countries get out of the default state with 0 wealth, this can be written as $V_{p}^{c}(0)>V_{p}^{a}$.

\section{F.2 Existence conditions with $q>\beta$}

For $q>\beta$, the amount of liquidity chosen by a productive participating country $B_{0}$ and the equilibrium outcome are determined by the same equations as in the market economy. The equilibrium construction of the default horizon $D$ ensures that all participating countries are 
better-off in the IFI risk-sharing arrangement. The additional participation constraint can be thus written as $V_{p}^{c}(0)>V_{p}^{a}$. It ensures that countries out of the default state join the IFI risksharing arrangement when all countries not in the default state participate in this arrangement.

\section{G The Hegemon economy}

We here follow Farhi and Maggiori (2018) and introduce a country called the Hegemon into the previous economy. This country has a positive mass $m$ and internalizes the impact of its choices on the asset price. More precisely, we consider the case where a country is larger than other countries and wields market power on the world financial market. This extension aims to show that the main results of our analysis are robust to the relaxation of the assumption of perfectly symmetric countries. In particular, even in this environment, excess default remains at the equilibrium, and an international liquidity provider can restore constrained-efficiency. The Hegemon has the same preferences as any other country. Clearing on the world financial market can now be expressed as follows:

$$
m B^{H}+\int_{i \in I} q\left(B^{i}, s^{i}\right) B^{\prime i} G(d i)=0
$$

where $B^{H}$ denotes the net borrowing demand of the Hegemon. Other notation remains unchanged.

As the Hegemon has a positive mass, it internalizes the effect of its (net) borrowing demand $B^{H}$ on the price of the world safe asset $q\left(B^{H}\right)$ :

$$
\begin{aligned}
V^{H}\left(B^{H}, X\right) & =\max _{\left\{c^{H}, B^{H^{\prime}}\right\}} u\left(c^{H}\right)+\beta V^{H}\left(B^{H^{\prime}}, X^{\prime}\right), \\
\text { s.t. } c^{H} & =y^{H}+B^{H}-q\left(B^{H^{\prime}}\right) B^{H^{\prime}} .
\end{aligned}
$$

The asset choice of the Hegemon is derived by the solution of the problem (94)-(95). Even though the function $B \mapsto q(B)$ may be discontinuous, it can be shown to be globally decreasing. Furthermore, we can use the results of Clausen and Strub (2020) (see in particular their section 3.2 ) to show that the optimum is characterized by the first-order condition $q\left(B^{H}\right)+q^{\prime}\left(B^{H^{\prime}}\right) B^{H^{\prime}}=$ $\beta$, which implies that the equilibrium price is strictly above $\beta$. 
The quasi-planner aims at maximizing the instantaneous aggregate utility $\tilde{U}$ expressed as:

$$
\begin{aligned}
\tilde{U} & =m u\left(\tilde{c}^{H}\right)+\sum_{k=-1}^{\tilde{D}-1} \tilde{n}_{k 0}\left(u\left(\tilde{c}_{0}\right)-\tilde{l}_{k 0}\right)+\sum_{k=1}^{\tilde{D}-1} \tilde{n}_{k}\left(u\left(\tilde{c}_{k}\right)-\bar{l}\right) \\
& +\tilde{n}_{p}^{d}\left(u\left(c_{0}\right)-c_{0}\right)+\tilde{n}_{u}^{d}(u(\bar{l})-\bar{l}),
\end{aligned}
$$

where the tilde on variables highlights their dependence in $\tilde{D}$. The following proposition characterizes the constrained-efficient equilibrium.

Proposition 7 (Constrained-efficient allocation) Either the constrained-efficient allocation is autarky or it is characterized by:

- the asset price is equal to $\tilde{q}=\beta$;

- there is full insurance: $\tilde{c}_{k}=\tilde{c}^{H}=u^{\prime-1}(1)$ for $k=0, \ldots, \tilde{D}-1$;

- the net position $\tilde{B}^{H}$ of the Hegemon is determined by the sign of $u^{\prime-1}(1)-y^{H}$. If it is positive and $u^{\prime-1}(1) \geq y^{H}$, then the Hegemon is a net lender, and if the opposite holds, then the Hegemon is a net borrower.

The proof is the following. In the Hegemon economy, the quasi-planner program can be expressed recursively as follows:

$$
\tilde{W}=\max _{\left\{\tilde{l}_{k 0}\right\}_{-1 \leq k<\tilde{D}-1},\left\{\tilde{c}_{k}\right\}_{1 \leq k<\tilde{D}, \tilde{D}-1},\left\{\tilde{B}_{k}\right\}_{0 \leq k<\tilde{D}-1}, \tilde{B}^{H^{\prime}}} \quad \tilde{U}+\beta \tilde{W}^{\prime},
$$

subject to the set of country budget constraints (similar to (13)-(15) in the market economy):

$$
\begin{aligned}
\tilde{B}_{k-1} & =\tilde{c}_{k}-\bar{l}+\tilde{q} \tilde{B}_{k}, \quad 1 \leq k<\tilde{D}-1, \\
\tilde{B}_{\tilde{D}-2} & =\tilde{c}_{D-1}-\bar{l}+\tilde{q}(1-\rho) \tilde{B}_{\tilde{D}-1}, \\
\tilde{c}_{0}+\tilde{q} \tilde{B}_{0} & =\tilde{l}_{k 0}+\tilde{B}_{k}, \quad-1 \leq k \leq \tilde{D}-1, \\
\tilde{c}^{H} & =y^{H}+\tilde{B}^{H}-\tilde{q} \tilde{B}^{H^{\prime}} .
\end{aligned}
$$

and subject to participation constraints (similar to (25) in the market economy): $\tilde{V}_{k 0} \geq \tilde{V}_{p}^{a}, \quad-1 \leq$ $k<D$ and $\tilde{V}_{k} \geq \tilde{V}_{u}^{a}, \quad 1 \leq k<D$. The planner understands the effect of the saving decisions 
of the Hegemon and of all other countries on the safe asset price.

$$
\sum_{k=0}^{\tilde{D}-2} \tilde{n}_{k} \tilde{B}_{k}+(1-\rho) \tilde{n}_{\tilde{D}-1} \tilde{B}_{\tilde{D}-1}+m \tilde{B}^{H^{\prime}}=0 .
$$

Euler equations can be written as:

$$
\begin{aligned}
\tilde{q}+\lambda & =\beta\left(\alpha+(1-\alpha) u^{\prime}\left(\tilde{c}_{1}\right)\right), \\
\tilde{q} u^{\prime}\left(\tilde{c}_{k}\right)+\lambda & =\beta\left(1-\rho+\rho u^{\prime}\left(\tilde{c}_{k+1}\right)\right), \quad 1 \leq k \leq \tilde{D}-2, \\
\tilde{q} u^{\prime}\left(\tilde{c}_{\tilde{D}-1}\right)+\lambda & \geq \beta, \text { and } \tilde{q}+\lambda=\beta .
\end{aligned}
$$

The price is determined by the following first-order condition:

$$
\begin{aligned}
0 & =m u^{\prime}\left(\tilde{c}^{H}\right) B^{H^{\prime}}+\sum_{k=-1}^{D-1} n_{k}^{p} B_{k} u^{\prime}\left(c_{k}^{p}\right)+\sum_{k=1}^{D-2} n_{k}^{u} B_{k}^{u} u^{\prime}\left(c_{k}^{u}\right) \\
& +n_{D-1}^{u}(1-\rho) B_{D-1}^{u} u^{\prime}\left(c_{D-1}^{u}\right) .
\end{aligned}
$$

An equilibrium is $u^{\prime}\left(\tilde{c}^{H}\right)=1$. We obtain: $u^{\prime-1}(1)=y^{H}+(1-\tilde{q}) \tilde{B}^{H}$ and $\tilde{B}^{H}=-\frac{y^{H}-u^{\prime-1}(1)}{1-\beta}$, which concludes the proof.

The novel part of the Proposition consists in the characterization of the net position of the Hegemon. The budget constraint (95) of the Hegemon coupled with the two first points of Proposition 7 imply that the net borrowing position of the Hegemon is defined by $\tilde{B}^{H}=$ $\frac{u^{\prime-1}(1)-y^{H}}{1-\beta}$, thereby proving the last point. Another take-away of Proposition 7 is that when the Hegemon internalizes the effect of its choices on the asset price, then the market allocation is not constrained-efficient.

The asset price at the market equilibrium is higher, and the equilibrium features imperfect insurance. Defaults at the equilibrium are too high, because there are insufficient safe assets in the economy. In other words, the result found for the symmetric equilibrium, where there is excess default at the equilibrium, still holds in the presence of a Hegemon with financial market power. As in the symmetric economy, an IFI providing liquidity to all countries can increase the aggregate welfare. The IFI turns out to be a net liquidity provider, which induces a fall in the price of liquidity and neutralizes the market power of the Hegemon. 